\title{
Protective mechanisms of melatonin against selenium toxicity in Brassica napus: insights into physiological traits, thiol biosynthesis and antioxidant machinery
}

Zaid Ulhassan ${ }^{1}$, Qian Huang ${ }^{1}$, Rafaqat Ali Gill ${ }^{2}$, Skhawat Ali ${ }^{1}$, Theodore Mulembo Mwamba ${ }^{1}$, Basharat Ali ${ }^{3}$, Faiza Hina ${ }^{4}$ and Weijun Zhou ${ }^{1 *}$ (i)

\begin{abstract}
Background: The ubiquitous signaling molecule melatonin (N-acetyl-5-methoxytryptamine) (MT) plays vital roles in plant development and stress tolerance. Selenium (Se) may be phytotoxic at high concentrations. Interactions between MT and Se (IV) stress in higher plants are poorly understood. The aim of this study was to evaluate the defensive roles of exogenous MT ( $0 \mu \mathrm{M}, 50 \mu \mathrm{M}$, and $100 \mu \mathrm{M})$ against Se (IV) $(0 \mu \mathrm{M}, 50 \mu \mathrm{M}, 100 \mu \mathrm{M}$, and $200 \mu \mathrm{M})$ stress based on the physiological and biochemical properties, thiol biosynthesis, and antioxidant system of Brassica napus plants subjected to these treatments.

Results: Se (IV) stress inhibited B. napus growth and biomass accumulation, reduced pigment content, and lowered net photosynthetic rate $\left(P_{n}\right)$ and PSIl photochemical efficiency ( $\left.F v / F m\right)$ in a dose-dependent manner. All of the aforementioned responses were effectively alleviated by exogenous MT treatment. Exogenous MT mitigated oxidative damage and lipid peroxidation and protected the plasma membranes from Se toxicity by reducing Se-induced reactive oxygen species (ROS) accumulation. MT also alleviated osmotic stress by restoring foliar water and sugar levels. Relative to standalone Se treatment, the combination of MT and Se upregulated the ROS-detoxifying enzymes SOD, APX, GR, and CAT, increased proline, free amino acids, and the thiol components GSH, GSSG, GSH/GSSG, NPTs, PCs, and cys and upregulated the metabolic enzymes $\gamma$-ECS, GST, and PCS. Therefore, MT application attenuates Se-induce oxidative damage in plants. MT promotes the accumulation of chelating agents in the roots, detoxifies Se there, and impedes its further translocation to the leaves.

Conclusions: Exogenous MT improves the physiological traits, antioxidant system, and thiol ligand biosynthesis in $B$. napus subjected to Se stress primarily by enhancing Se detoxification and sequestration especially at the root level. Our results reveal better understanding of Se-phytotoxicity and Se-stress alleviation by the adequate supply of MT. The mechanisms of MT-induced plant tolerance to Se stress have potential implications in developing novel strategies for safe crop production in Se-rich soils.
\end{abstract}

Keywords: Antioxidants, Oilseed rape, Osmolytes, Oxidative stress, Plant growth regulator, Selenium, Thiols

\footnotetext{
* Correspondence: drragill@caas.cn; wjzhou@zju.edu.cn

${ }^{2}$ Oil Crops Research Institute, Chinese Academy of Agricultural Sciences, Wuhan 430062, China

${ }^{1}$ Institute of Crop Science, Ministry of Agriculture and Rural Affairs Key

Laboratory of Spectroscopy Sensing, Zhejiang University, Hangzhou 310058,

China

Full list of author information is available at the end of the article
}

(c) The Author(s). 2019 Open Access This article is distributed under the terms of the Creative Commons Attribution 4.0 International License (http://creativecommons.org/licenses/by/4.0/), which permits unrestricted use, distribution, and reproduction in any medium, provided you give appropriate credit to the original author(s) and the source, provide a link to the Creative Commons license, and indicate if changes were made. The Creative Commons Public Domain Dedication waiver (http://creativecommons.org/publicdomain/zero/1.0/) applies to the data made available in this article, unless otherwise stated. 


\section{Highlights}

$\gg$ Excessive Se inhibits the plant growth, biomass accumulation and impairs photosynthesis

$\gg$ Se causes osmotic stress and modulates the thiol metabolism

$\gg$ Se induces oxidative injuries by desynchronizing the ROS-detoxifying enzyme activities

$\gg$ Exogenous MT protects the physio-biochemical traits by scavenging Se-oxidative damages

$\gg$ MT enhances plant tolerance by inducing thiols accumulation to sequester Se in roots.

\section{Background}

The naturally occurring metalloid selenium (Se) is an essential micronutrient/trace element for human and certain animals. However, its effect and importance in plants remain controversial [1]. The essentiality and phytotoxicity of Se may depend on dose, speciation, and target species [2]. Over the past few decades, Se levels have been rising in agricultural soils and could be toxic to plants, humans, and animals [3]. Fossil fuel combustion, mining, irrigation, and industrial discharge are the main sources of large-scale Se pollution [4]. Soil selenium content normally ranges from $0.01-2 \mathrm{mg} \mathrm{kg}^{-1}$. However, in certain regions such as Hubei Province, China, soil Se levels are excessive (>10 $\mathrm{mg} \mathrm{kg}^{-1}$ ) [5]. Selenite (IV) and selenate (VI) are the mains forms of Se available for plant uptake in soils. While, selenite is transported by phosphate transporters and selenate is mediated by sulfate transporters in different plants [6]. At very high concentrations, both Se-forms are phytotoxic. Nevertheless, Se (IV) is more injurious to plants than $\mathrm{Se}(\mathrm{VI})$ and is problematic for farmers $[6,7]$. Plants grown in Se-contaminated soils present with chlorosis and stunted growth [8]. Se overdose may perturb photosynthesis, induce reactive oxygen species (ROS) production, and damage plasma membranes by promoting lipid peroxidation [9-11]. In response to oxidative stress, plants produce antioxidant enzymes such as superoxide dismutase (SOD), peroxidase (POD), catalase (CAT), ascorbate peroxidase (APX), and glutathione reductase (GR). Plants also produce thiol ligands such as non-protein thiols (NPTs), cysteine (cys), reduced glutathione (GSH), oxidized glutathione (GSSG), and phytochelatins (PCs) to chelate and detoxify metals and metalloids [12-14].

Melatonin ( $N$-acetyl-5-methoxytryptamine) (MT) is a ubiquitous signal molecule with pleiotropic effects and plays regulatory roles for animals and plants. In animals, MT regulates circadian sleep-wake cycle and seasonal reproduction (not in case of plants). Plant ability to synthesize MT in dual organelles (mitochondria and chloroplast) [15]. In higher plants, MT was first discovered in 1995 [16]. It (MT) performs diverse physiological functions such as plant protection against environmental stresses. For this, plants usually enhance endogenous
MT production [17]. Under stress conditions, MT promotes plant growth, delays senescence, and modulates photoperiod responses and root architecture [18]. MT may also protect plants against abiotic stressors such as heat [19], cold [20], salt [21], drought [22] and heavy metals [23]. MT augments plant stress tolerance by inducing the enzymatic detoxification of free radicals and reactive oxygen species (ROS) [24] and by scavenging excess ROS [23-25]. However, the crosstalk between MT and metalloids such as Se (IV) is poorly understood and merits further investigation.

Oilseed rape (Brassica napus L.) is widely grown as a source of edible oil. It can resist the phytotoxic effects of chromium [26-28], cadmium [29, 30], cobalt [31, 32], beryllium [33], and selenium [10, 11]. Recent reports suggested that $50 \mu \mathrm{mol} \mathrm{kg}{ }^{-1}$ exogenous MT applied to Cyphomandra betacea [34] and $100 \mu \mathrm{mol} \mathrm{L}^{-1}$ exogenous MT treatment on Malachium aquaticum and Galinsoga parviflora [35] alleviated cadmium (Cd) toxicity by improving plant growth, photosynthesis, and antioxidant systems. It was reported that $100 \mu \mathrm{M}$ MT induced the highest antioxidant, GSH, PC, and $\mathrm{Cd}$ sequestration levels of all doses tested on tomato [12]. Interactions between MT and Se were recently reported to mitigate $\mathrm{Cd}$ toxicity in tomato plants [36]. However, the roles of MT in attenuating Se (IV) phytotoxicity in higher plants) remain unknown. Thiols such as GSH and PCs have proven chelating, antioxidant, and stress tolerance induction properties in plants. However, the mechanisms of MT-prompted thiol biosynthesis and MT-associated Se (IV) resistance in higher plants have not been fully elucidated.

Here, we investigated the influences of MT on Se (IV) stress in higher plants and attempted to uncover the biochemical mechanisms involved. We proposed that MT may play a defensive role in Se (IV) tolerance and participate in other physiological processes besides chelation and antioxidation. We suggested that the forms and levels of thiols induced by plants in response to selenium stress may serve as biomarkers for MT-facilitated Se (IV) stress responses. The aim of the present study was to elucidate the MT-induced mechanisms affecting the physiological and biochemical properties of $B$. napus tissues and their osmotic metabolites and thiol metabolism under Se (IV) stress. This information may be used to assess and mitigate the risks of contamination in food crops raised on soils with elevated Se (IV) burdens.

\section{Methods}

\section{Plant materials and experimental design}

The seeds of black-seeded cultivar ZS (Zheshuang) 758 of $B$. napus (oilseed rape) were obtained from the College of Agriculture and Biotechnology, Zhejiang University, China. The above cultivar was tested previously [11, 37, 
38] as tolerant against different heavy metals/metalloids. The seeds were sterilized and germinated at $25^{\circ} \mathrm{C}$ in the dark on filter paper in Petri dishes. Germinated seeds were planted in plastic pots $(170 \mathrm{~mm} \times 220 \mathrm{~mm})$ containing peat soil. They were maintained in the greenhouse with the following conditions: light intensity of $400 \mu \mathrm{mol} \mathrm{m}^{-2}$ $\mathrm{s}^{-1}$, temperature of $16-20^{\circ} \mathrm{C}$ and relative humidity of $60 \%$. After the emergence of the fifth leaf, uniform-sized seedlings were picked and shifted into plate holes on plastic pots (five plants per pot) having half-strength Hoagland nutrient solution [39]. The nutrient solution was aerated constantly with the air pump. The composition of Hoagland solution was as follows (in $\mu \mathrm{mol} / \mathrm{L}$ ): $3000 \mathrm{KNO}_{3}$, $2000 \mathrm{Ca}\left(\mathrm{NO}_{3}\right)_{2}, 1000 \mathrm{MgSO}_{4}, 10 \mathrm{KH}_{2} \mathrm{PO}_{4}, 12 \mathrm{FeC}_{6} \mathrm{H}_{6} \mathrm{O}_{7}$, $500 \mathrm{H}_{3} \mathrm{BO}_{3}, 800 \mathrm{ZnSO}_{4}, 50 \mathrm{MnCl}_{2}, 300 \mathrm{CuSO}_{4}, 100$ $\mathrm{Na}_{2} \mathrm{MoO}_{4}$. The $\mathrm{pH}$ of the solution was maintained at 6.0. Each treatment contains four pots (replicates) and nutrient solution was re-filled after every four days. After an acclimatization period of eight days, Se was supplied as sodium selenite $\left(\mathrm{Na}_{2} \mathrm{SO}_{3}\right)$ by making the desired concentrations $(0 \mu \mathrm{M}, 50 \mu \mathrm{M}, 100 \mu \mathrm{M}, 200 \mu \mathrm{M})$ and simultaneously supplied MT $(50 \mu \mathrm{M}$ and $100 \mu \mathrm{M})$ into the full-strength Hoagland solution. The treatments used were: (1) control (Ck), (2) $50 \mu \mathrm{M}$ Se (IV) alone, (3) $100 \mu \mathrm{M}$ Se (IV) alone, (4) $200 \mu \mathrm{M}$ Se (IV) alone, (5) $50 \mu \mathrm{M}$ MT alone, (6) $100 \mu \mathrm{M}$ MT alone, (7) $50 \mu \mathrm{M}$ Se (IV) $+50 \mu \mathrm{M}$ MT, (8) $50 \mu \mathrm{M}$ Se (IV) + $100 \mu \mathrm{M}$ MT, (9) $100 \mu \mathrm{M}$ Se (IV) + $50 \mu \mathrm{M}$ MT, (10) $100 \mu \mathrm{M}$ Se (IV) $+100 \mu \mathrm{M}$ MT, (11) $200 \mu \mathrm{M}$ Se (IV) $+50 \mu \mathrm{M}$ MT, and (12) $200 \mu \mathrm{M}$ Se (IV) $+100 \mu \mathrm{M}$ MT. The selected treatment concentrations were established on the basis of preexperimental studies, in which different (lower to higher) levels of $\mathrm{Se}$ (IV) as $0 \mu \mathrm{M}, 50 \mu \mathrm{M}, 100 \mu \mathrm{M}$, $200 \mu \mathrm{M}, 300 \mu \mathrm{M}, 400 \mu \mathrm{M}$ and $500 \mu \mathrm{M}$ of $\mathrm{Na}_{2} \mathrm{SO}_{3}$ and MT $(0 \mu \mathrm{M}, 25 \mu \mathrm{M}, 50 \mu \mathrm{M}, 100 \mu \mathrm{M}$ and $200 \mu \mathrm{M})$ were applied. The Se (IV) at $50 \mu \mathrm{M}$ showed slight injuries on plant growth and significant visible damages were prominent at $100 \mu \mathrm{M}$ Se (IV). While Se (IV) doses higher than $200 \mu \mathrm{M}$ were too toxic for plant growth. In case of MT application, plants exhibited optimum response at $50 \mu \mathrm{M}$ and $100 \mu \mathrm{M}$ MT under Se (IV) stress conditions. The selection of particular (phosphate/silicon) transporter genes was made on the basis of our pre-experimental findings. In preliminary studies, we performed the expression analysis for phosphate (OsPT1, OsPT2, OsPT4, OsPT6, and OsPT10), sulfate (SulTR1), and silicon (Lsi2) transporter genes to find out the potential candidate gene for selenite uptake in the leaves and roots of $B$. napus. These transporter genes (OsPT2 and Lsi2) were selected due to their relatively higher abundance. Usually plants up-regulated the expression of phosphate transporter genes in roots $[6,40,41]$. Therefore, we targeted plant roots for the gene expression of these transporters. The experiment was terminated after fifteen days of Se (IV) and MT (alone and combine) treatments. Then plants were harvested for the physio-biochemical, metabolic and anatomical studies.

\section{Morphological parameters and relative water content (RWC)}

Directly after harvesting, fresh biomass of leaves and roots was measured according to [42]. Then plant samples were oven-dried $\left(70{ }^{\circ} \mathrm{C}\right)$ for $4 \mathrm{~h}$. The measurement of full plant lengths, root and leaf area was done according to [26]. Fully stretched fresh leaves (fourth from the apex) per replicate were used for the determination of RWC as reported by [43-45] with minor adjustments. In details, fresh leaves (without midrib) were weighed directly and floated on the surface of deionized distilled water (DDW) in Petri dishes to soak water for the next $48 \mathrm{~h}$ in dark. The sticking water of leaf parts was blotted and turgor weight was noted. After dehydrating these samples at $70^{\circ} \mathrm{C}$ for $48 \mathrm{~h}$, dry weights were obtained. RWC was calculated by the below formula:

$$
\text { RWC }=\frac{\text { Fresh weight-Dry weight }}{\text { Turgid weight-Dry weight }} \times 100
$$

\section{Pigment contents, gas exchange, and chlorophyll fluorescence measurement}

The light harvesting pigment contents including chlorophylls $(a, b)$ and carotenoids were extracted from the upper second fully developed leaves with $96 \%$ (v/v) ethanol as reported earlier [11]. Net photosynthetic rate $(P n)$ was recorded using an infrared gas analyzer (IRGA) portable photosynthesis system (Li-Cor 6400, Lincoln, NE, USA) as reported by [32]. For the determination of maximum quantum efficiency of photosystem II $(F v /$ $F m$ ), second fully expanded leaves were first reserved in the dark adaptation for $20 \mathrm{~min}$ and then measurement of $F v / F m$ was carried by an imaging pulse-amplitudemodulated (PAM) fluorimeter (IMAG-MAXI; Heinz Walz, Effeltrich, Germany) [46].

\section{Extraction and quantification of endogenous se and MT by HPLC-MS}

The endogenous Se in plant tissues was extracted by the method as reported earlier [11]. The measurement of endogenous plant MT was carried out with some modifications [47]. Fresh samples ( $0.5 \mathrm{~g})$ of leaf and root were grounded and homogenized in $5 \mathrm{~mL}$ methanol containing $50 \mathrm{ng} \mathrm{mL}{ }^{-1}\left[{ }_{2} \mathrm{H}^{6}\right]-\mathrm{MT}$ (Toronto Research Chemicals Ltd., Toronto, Ontario, Canada) which was used as internal standard. After shaking the homogenate overnight in the dark at $4{ }^{\circ} \mathrm{C}$ and centrifuged at $15,000 \mathrm{~g}$ for 10 
min. Later after transferring the supernatant into a new tube, the segments were again extracted with $2 \mathrm{~mL}$ of methanol and mixed with the fraction of supernatant. For the purification of MT, the supernatant was transferred to the $\mathrm{C}^{18}$ solid-phase extraction (SPE) cartridge (Waters, Milford, MA, USA). Then extracted material was rigorously dehydrated under nitrogen. The obtained residue was dissolved in $0.5 \mathrm{~mL}$ of methanol (70\%) and subjected to HPLC electrospray ionization/MS-MS analysis on an Agilent 6460 triple quad LC/MS with an Agilent-XDB ${ }^{18}$ column $(2.1 \mathrm{~mm} \times 150 \mathrm{~mm}$, an Agilent Technologies, Frankfurt, Germany). The recovery rate was estimated by the quantification of $\left[{ }_{2} \mathrm{H}^{6}\right]-\mathrm{MT}$ as an internal standard [48].

\section{Soluble sugar, free amino acids and proline contents}

The method reported by [49] was adapted for the estimation of soluble sugar contents. The estimation of total free amino acids and proline contents was done according to the methods used by $[50,51]$ respectively.

\section{Quantification of MDA, ROS, relative electrolyte leakage (REL) and histochemical identification of $\mathrm{H}_{2} \mathrm{O}_{2}$ and $\mathrm{O}_{2}{ }^{-{ }^{-}}$as stress markers}

The contents of $\mathrm{H}_{2} \mathrm{O}_{2}, \mathrm{O}_{2}{ }^{\cdot-}$ and MDA were determined by following the method described by [32]. Little changes were adopted in TBA method used for MDA determination. Fresh samples $(0.2 \mathrm{~g})$ were homogenized, extracted in $10 \mathrm{~mL}$ of $0.25 \%$ TBA made in $10 \%$ trichloroacetic acid (TCA). Then extracted material was heated for $30 \mathrm{~min}$ at $95^{\circ} \mathrm{C}$ and ice-cooled to terminate the reaction. After centrifuging the cooled mixture at 10 , $000 \mathrm{~g}$ for $10 \mathrm{~min}$, the absorbance of the supernatant was measured at $532 \mathrm{~nm}$. Non-specific turbidity was corrected by subtracting the absorbance values taken at $600 \mathrm{~nm}$ and MDA levels were calculated using an extinction coefficient of $155 \mathrm{mM}^{-1} \mathrm{~cm}^{-1}$. The accumulation of $\mathrm{H}_{2} \mathrm{O}_{2}$ and $\mathrm{O}_{2}{ }^{--}$in $B$. napus roots was identified by staining with 3, 3-diaminobenzidine (DAB) and nitroblue tetrazolium (NBT) as done by [38]. For REL, root $(0.1 \mathrm{~g})$ sections were shaken for $30 \mathrm{~min}$ in deionized water and, then the conductivity of the bathing medium (EC1) was measured. Again, the samples were boiled for $15 \mathrm{~min}$ and second conductivity was measured (EC2) [52]. Total electrical conductivity was determined by using the below formula.

$$
\operatorname{REL}(\%)=\left(\frac{\mathrm{EC} 1}{\mathrm{EC} 2}\right) \times 100
$$

\section{ROS-detoxifying enzymes}

For enzymes analysis, leaf and root samples ( $0.5 \mathrm{~g}$ each)

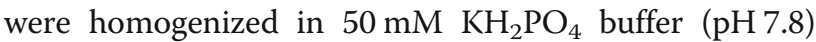

and centrifuged at 10,000 g (Eppendorf AG, model 2231, Hamburg, Germany). The floating liquid (above precipitate) was taken for the analysis of subsequent enzyme activities. Total superoxide dismutase (SOD, EC 1.15.1.1) was determined by following the method of [53]. Peroxidase (POD, EC.11.1.7) activity was determined by [54] with minor adjustments. The reaction mixture com-

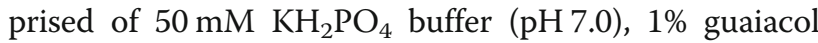
$\left(\mathrm{C}_{7} \mathrm{H}_{8} \mathrm{O}_{2}\right), 0.5 \% \mathrm{H}_{2} \mathrm{O}_{2}$ and $100 \mu \mathrm{L}$ enzyme extract. The alterations owing to guaiacol were estimated at $470 \mathrm{~nm}$. Catalase (CAT, EC 1.11.1.6) was determined by [55] with the use of $\mathrm{H}_{2} \mathrm{O}_{2}$ (extinction co-efficient $39.4 \mathrm{mM} \mathrm{cm}^{-1}$ ). Glutathione reductase (GR, EC 1.6.4.2) activity was assayed by following the method of [56] with NADPH oxidation at $340 \mathrm{~nm}$ (extinction coefficient $6.2 \mathrm{mM} \mathrm{cm}^{-}$ ${ }^{1}$ ). The assay for ascorbate peroxidase (APX, EC 1.11.1.11) activity was measured by [57] with slight changes. The alterations in reaction mixture were as $100 \mathrm{mM} \mathrm{KH_{2 }} \mathrm{PO}_{4}$ buffer (pH 7.0), $0.1 \mathrm{mM}$ EDTA-Na ${ }_{2}$, $0.05 \mathrm{H}_{2} \mathrm{O}_{2}, 0.3 \mathrm{mM}$ ascorbic acid, and $100 \mu \mathrm{L}$ protein extract. The absorbance was checked at $290 \mathrm{~nm}$ after $30 \mathrm{~s}$ of $\mathrm{H}_{2} \mathrm{O}_{2}$ addition.

\section{Estimation of thiol compounds and observation of leaf stomata by scanning electron microscopy (SEM)}

The estimation of non-protein thiol (NPT), and reduced and oxidized glutathione (GSH and GSSG), respectively) was carried out according to [58]. The concentration of phytochelatins (PCs) was determined as $\mathrm{PCs}=\mathrm{NPT}-(\mathrm{GSH}+\mathrm{GSSG})$ [59]. For SEM, leaf samples were immediately fixed with $2.5 \%$ glutaraldehyde and then postfixed with $1 \% \mathrm{OsO}_{4}$ in $(0.1 \mathrm{M})$ phosphate-buffered saline (PBS; pH 6.8) to evade any damage during sample preparation. The fixed leaves were dehydrated in a graded ethanol solution, transferred to alcohol + iso-amyl acetate $(1: 1, \mathrm{v} / \mathrm{v})$ mixture, and then transferred to pure iso-amyl acetate. In the end, samples were vacuum-dried in Hitachi Model HCP-2 with liquid $\mathrm{CO}_{2}$ and coated with goldpalladium in Hitachi Model E-1010 ion sputter. The SEM observations were made with an S-4800 microscope (Hitachi Led., Tokyo, Japan, Model TM-1000).

\section{Extraction of total RNA and quantitative real-time PCR (qRT-PCR) assays}

Total RNA from leaf and root (about $100 \mathrm{mg}$ ) tissues was excerpted manually by a Trizol method. To eliminate the genomic DNA (gDNA) and cDNA synthesis, we used Prime scriptTM RT reagent with gDNA eraser kit (Takara, Co. Ltd., Japan). The synthesized cDNA from different treatment was assayed for quantitative realtime (qRT-PCR) in the iCycler iQTM Real-time detection system (Bio-Rad, Hercules, CA, USA) by using SYBR $^{\circ}$ Premix Ex Taq II (Takara, Co. Ltd., Japan). 
Primers for targeted phosphate/silicon genes were obtained from the sequence database of NCBI (http:// www.ncbi.nlm.nih.gov). The sequence $\left(5^{\prime} \rightarrow 3^{\prime}\right)$ of forward (F) and reverse (R) primers are given in Additional file 1: Table S2. The PCR conditions were established by adopting the method of [60].

\section{Statistical analysis}

The significant differences were investigated among the physio-biochemical, osmolytes and phytochelatins data. The results represent the mean \pm standard deviation of four to six (minimum three) replicates. Data was analyzed by using statistical package, SPSS version 16 (Chicago, IL, USA). A two-way variance analysis (ANOVA) was used followed by Duncan's Multiple Range Test (DMRT) $(P<0.05)$. For supplementary data, two-way ANOVA and $\beta$-coefficients were used followed by Duncan's Multiple Range Test (DMRT) with significances at $P, 0.05$ and 0.01 [61]. The graphs were prepared by plotting data in Origin Pro version 8.0 (Origin Lab Corporation, Wellesley Hills, Wellesley, MA, USA).

\section{Results}

Se-induced endogenous MT biosynthesis and exogenous MT reduce se uptake in plant tissues

To determine the effects of exogenous selenium (Se) on endogenous melatonin (MT) biosynthesis and Se uptake, we measured endogenous MT and Se accumulation in B. napus leaves and roots at various Se doses (Additional file 1: Table S1). For the control, there were nonsignificant $(P \geq 0.05)$ differences between the leaf and root in terms of Se content. Substantial increases in leaf and root Se content with increasing Se dose $(50 \mu \mathrm{M}$, $100 \mu \mathrm{M}$, and $200 \mu \mathrm{M}$ ) were observed relative to the controls. Maximum increases in Se content were measured at $200 \mu \mathrm{M}$ Se. The accumulation in the roots was $1367.21 \mathrm{mg} \mathrm{kg}^{-1} \mathrm{DW}$ and in the leaves it was $285.60 \mathrm{mg}$ $\mathrm{kg}^{-1}$ DW. Endogenous MT content and MT induction also increased with Se dose. In contrast, the MT concentrations remained nearly constant in the leaves and roots under non-stress conditions. The Se-treated plants displayed maximum MT biosynthesis at $200 \mu \mathrm{M}$ Se. At this dosage, the MT levels in the leaves and roots were 59 and $65 \%$ and 76 and $85 \%$ higher than those at the $50 \mu \mathrm{M}$ Se and $100 \mu \mathrm{M}$ Se dosages, respectively. These findings confirmed that exogenous Se induces endogenous MT accumulation in $B$. napus tissues. Selenium accumulation was significantly $(P \leq 0.05)$ more enhanced in the roots than the leaves with increasing Se doses (Additional file 1: Table S1). This phenomenon implies reduced Se translocation to the leaves and greater Se accumulation in the roots. Exogenous MT reduced Se uptake and translocation in plant tissues. Relative to the control, the $100 \mu \mathrm{M}$ MT treatment significantly $(P \leq$
0.05) reduced plant Se content by 58 and 61\%, 33 and $34 \%$, and 21 and $22 \%$ in the leaves and roots at $50 \mu \mathrm{M}$, $100 \mu \mathrm{M}$, and $200 \mu \mathrm{M}$ Se, respectively. These findings confirmed that exogenous Se induces the accumulation of endogenous Se and that exogenous MT + Se application reduces Se accumulation in $B$. napus leaves and roots.

Exogenous MT alleviates se-induced plant growth, biomass accumulation, and photosynthesis reductions Endogenous MT production in B. napus seedlings under Se stress suggests that MT participates in biochemical and physiological processes in the plant (Additional file 1: Table S1). We focused on Se-induced phenotypic changes in plant growth, biomass production (Table 1), and photosynthesis (Fig. 1a-f) in order to elucidate the mechanism by which MT mitigates Se stress. For the control, there were no significant differences $(P \geq 0.05)$ between MT level and Se concentration. Selenium at $50 \mu \mathrm{M}$ caused no significant changes in plant morphophysiology whereas $100 \mu \mathrm{M}$ Se slightly modified these attributes of B. napus. On the other hand, $200 \mu \mathrm{M}$ Se induced severe foliar chlorosis and significantly $(P \leq 0.05)$ reduced leaf fresh and dry biomass (49 and 46\%), root fresh and dry biomass (39 and 53\%), plant height (44\%), leaf area (32\%), Chl a (31\%), Chl b (43\%), carotenoids (45\%), net photosynthetic rate (54\%), and Fv/Fm (46\%) relative to the control. All doses of exogenous MT reversed the deleterious effects of Se. The $100 \mu \mathrm{M}$ MT + $50 \mu \mathrm{M}$ Se treatment dramatically increased leaf fresh and dry weight (8 and 17\%), root fresh and dry weight (25 and $17 \%)$, plant height (7\%), leaf area (6\%), Chl a (30\%), Chl $b$ (18\%), carotenoids (10\%), net photosynthetic rate (13\%), and Fv/Fm (14\%) compared with the other MT + Se combination treatments. Exogenous MT at $100 \mu \mathrm{M}$ was more efficacious than $50 \mu \mathrm{M}$ MT at attenuating the adverse effects of Se stress. Exogenous MT also mitigated growth inhibition in B. napus seedlings under Se stress.

\section{Exogenous MT improves metabolic compensation, mitigates oxidative damage, and maintains membrane integrity by reducing se stress}

To investigate the role of MT in Se-induced osmotic stress, we compared the relative water content (RWC), water-soluble sugar (WSG), free amino acid (FAA), and proline (Fig. 2a-c) levels among treatments. RWC and WSG decreased with increasing Se dose. The strongest reductions in RWC and WSG occurred at $200 \mu \mathrm{M}$ Se and they were significant $(P \leq 0.05)$. At this Se dosage, RWC and WSG were 56 and $74 \%$ lower than the they were in the control. Exogenously applied MT augmented the RWC and WSG diminished by Se exposure. Maximum RWG and WSG recovery was observed for the 
Table 1 Interactive effects of exogenous melatonin and selenium on plant morphological characteristics. Effects of different treatments of exogenous MT $(0 \mu \mathrm{M}, 50 \mu \mathrm{M}$ and $100 \mu \mathrm{M})$ and Se (Se) $(0 \mu \mathrm{M}, 50 \mu \mathrm{M}, 100 \mu \mathrm{M}$ and $200 \mu \mathrm{M})$ on the leaf fresh/dry weight (g), root fresh/dry weight $(\mathrm{g})$, plant height $(\mathrm{cm})$ and leaf area $\left(\mathrm{cm}^{2}\right.$ plant $\left.^{-1}\right)$ of Brassica napus cv. ZS 758

\begin{tabular}{llllllll}
\hline $\begin{array}{l}\text { MT conc. } \\
(\mu \mathrm{M})\end{array}$ & $\begin{array}{l}\text { Se conc. } \\
(\mu \mathrm{M})\end{array}$ & $\begin{array}{l}\text { Leaf fresh } \\
\text { weight }\end{array}$ & $\begin{array}{l}\text { Leaf dry } \\
\text { weight }\end{array}$ & $\begin{array}{l}\text { Root fresh } \\
\text { Weight }\end{array}$ & $\begin{array}{l}\text { Root dry } \\
\text { weight }\end{array}$ & Plant height & Leaf area \\
\hline 0 & 0 & $114.59 \pm 8.01 \mathrm{ab}$ & $7.49 \pm 0.72 \mathrm{ab}$ & $16.61 \pm 1.55 \mathrm{~cd}$ & $3.65 \pm 0.35 \mathrm{ab}$ & $25.68 \pm 2.43 \mathrm{ab}$ & $192.22 \pm 17.17 \mathrm{abc}$ \\
& 50 & $107.75 \pm 7.17 \mathrm{~b}$ & $7.04 \pm 0.69 \mathrm{bc}$ & $15.24 \pm 1.38 \mathrm{de}$ & $3.35 \pm 0.33 \mathrm{bc}$ & $24.61 \pm 2.40 \mathrm{bcd}$ & $185.73 \pm 16.57 \mathrm{abc}$ \\
& 100 & $91.08 \pm 6.20 \mathrm{c}$ & $5.84 \pm 0.55 \mathrm{~d}$ & $13.51 \pm 1.26 \mathrm{ef}$ & $2.77 \pm 0.22 \mathrm{~d}$ & $20.76 \pm 2.21 \mathrm{c}$ & $168.66 \pm 14.58 \mathrm{c}$ \\
& 200 & $58.76 \pm 4.76 \mathrm{~d}$ & $4.07 \pm 0.39 \mathrm{e}$ & $10.16 \pm 0.92 \mathrm{~g}$ & $1.73 \pm 0.17 \mathrm{e}$ & $14.36 \pm 1.68 \mathrm{~d}$ & $130.36 \pm 11.64 \mathrm{~d}$ \\
50 & 0 & $116.03 \pm 8.51 \mathrm{ab}$ & $7.71 \pm 0.75 \mathrm{ab}$ & $17.69 \pm 1.55 \mathrm{bc}$ & $3.77 \pm 0.34 \mathrm{ab}$ & $26.26 \pm 2.56 \mathrm{a}$ & $193.88 \pm 17.09 \mathrm{abc}$ \\
& 50 & $110.18 \pm 7.88 \mathrm{ab}$ & $7.58 \pm 0.73 \mathrm{ab}$ & $16.61 \pm 1.35 \mathrm{~cd}$ & $3.59 \pm 0.36 \mathrm{ab}$ & $25.09 \pm 2.32 \mathrm{ab}$ & $188.98 \pm 17.24 \mathrm{abc}$ \\
& 100 & $92.27 \pm 6.11 \mathrm{c}$ & $6.25 \pm 0.57 \mathrm{~cd}$ & $14.68 \pm 1.21 \mathrm{de}$ & $2.91 \pm 0.24 \mathrm{~cd}$ & $21.08 \pm 2.01 \mathrm{c}$ & $171.28 \pm 15.88 \mathrm{bc}$ \\
& 200 & $59.46 \pm 4.20 \mathrm{~d}$ & $4.34 \pm 0.42 \mathrm{e}$ & $10.99 \pm 0.89 \mathrm{~g}$ & $1.80 \pm 0.16 \mathrm{e}$ & $14.55 \pm 1.42 \mathrm{~d}$ & $132.11 \pm 12.22 \mathrm{~d}$ \\
100 & 0 & $121.03 \pm 8.87 \mathrm{a}$ & $8.28 \pm 0.77 \mathrm{a}$ & $20.53 \pm 1.84 \mathrm{a}$ & $4.04 \pm 0.38 \mathrm{a}$ & $28.74 \pm 2.73 \mathrm{a}$ & $198.01 \pm 17.25 \mathrm{a}$ \\
& 50 & $115.90 \pm 7.88 \mathrm{ab}$ & $8.26 \pm 0.80 \mathrm{a}$ & $19.09 \pm 1.79 \mathrm{ab}$ & $3.92 \pm 0.39 \mathrm{a}$ & $26.25 \pm 2.55 \mathrm{a}$ & $195.96 \pm 16.76 \mathrm{ab}$ \\
& 100 & $94.56 \pm 5.84 \mathrm{c}$ & $6.69 \pm 0.63 \mathrm{bcd}$ & $16.50 \pm 1.31 \mathrm{~cd}$ & $3.07 \pm 0.25 \mathrm{~cd}$ & $21.79 \pm 2.08 \mathrm{bc}$ & $175.08 \pm 15.01 \mathrm{abc}$ \\
& 200 & $60.75 \pm 4.02 \mathrm{~d}$ & $4.59 \pm 0.41 \mathrm{e}$ & $12.11 \pm 1.09 \mathrm{fg}$ & $1.86 \pm 0.15 \mathrm{e}$ & $14.80 \pm 1.47 \mathrm{~d}$ & $134.24 \pm 11.84 \mathrm{~d}$ \\
\hline
\end{tabular}

Values are means \pm St. Dev. $(n=3)$. Means of values followed by the same letters are not significantly differing at $P \leq 0.05$ according to Duncan's multiple range test

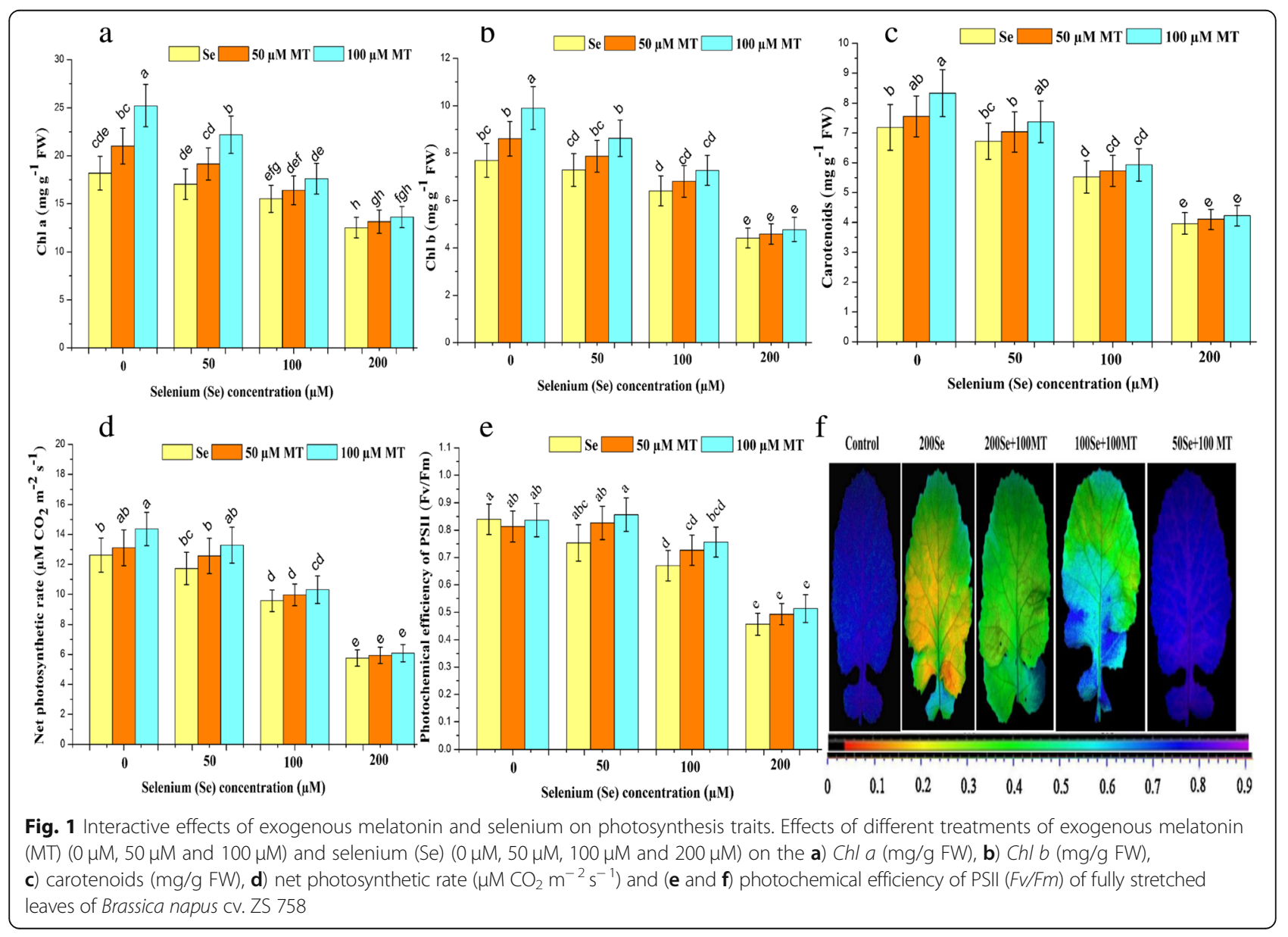




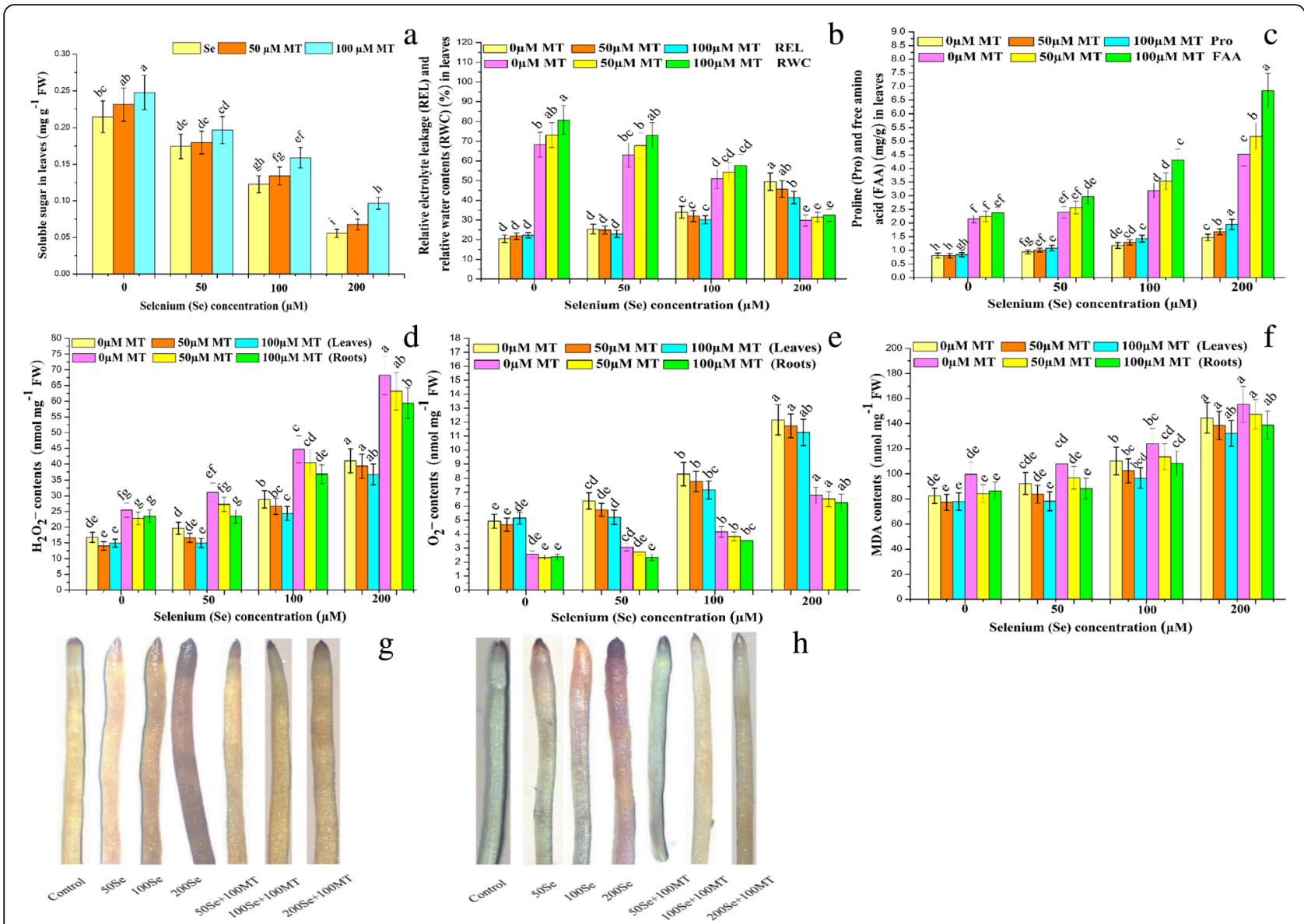

Fig. 2 Interactive effects of exogenous melatonin and selenium on osmotic metabolites, reactive oxidative species, relative electrolyte leakage, and histochemical staining. Effects of different treatments of exogenous melatonin (MT) $(0 \mu \mathrm{M}, 50 \mu \mathrm{M}$ and $100 \mu \mathrm{M})$ and selenium (Se) $(0 \mu \mathrm{M}, 50 \mu \mathrm{M}, 100 \mu \mathrm{M}$ and $200 \mu \mathrm{M}$ ) on the (a) soluble sugar ( $\mathrm{mg} / \mathrm{g} \mathrm{FW),} \mathrm{(b)} \mathrm{relative} \mathrm{electrolyte} \mathrm{leakage} \mathrm{( \% )} \mathrm{and} \mathrm{relative} \mathrm{water} \mathrm{content} \mathrm{( \% ),} \mathrm{(c)} \mathrm{proline} \mathrm{contents} \mathrm{(mg/g} \mathrm{FW)}$ and free amino acid (mg/g FW) in the leaves, and (d) $\mathrm{H}_{2} \mathrm{O}_{2}\left(\mathrm{nmol} \mathrm{mg}^{-1} \mathrm{FW}\right.$, (e) $\mathrm{O}_{2}^{-{ }^{-}}$(nmol mg ${ }^{-1} \mathrm{FW}$ ), (f) MDA (nmol mg- 1 FW) contents in the leaves and roots, and root staining with (g) 3,3-diaminobenzidine (DAB) and (h) nitro-blue tetrazolium (NBT) of Brassica napus Cv. ZS 758

$50 \mu \mathrm{M}$ Se treatment (16\%) and minimum recovery was detected for the $200 \mu \mathrm{M}$ Se treatment (9\%) (Fig. 2a and b). The standalone Se treatment significantly $(P \leq 0.05)$ increased FAA and proline compared with the control. The $50 \mu \mathrm{M}, 100 \mu \mathrm{M}$, and $200 \mu \mathrm{M}$ Se doses increased FAA and proline by 11 and 16\%, 48 and 46\%, and 109 and $82 \%$, respectively. Exogenously applied MT increased foliar FAA and proline with increasing Se dose. Maximum increases in FAA and proline were detected at $100 \mu \mathrm{M} \mathrm{MT}+200 \mu \mathrm{M}$ Se (51 and 32\% higher, respectively, than the other MT + Se treatments). The standalone MT treatment slightly increased foliar FAA and proline relative to the control (Fig. 2c).

The main plant biomarkers of oxidative damage, $\mathrm{H}_{2} \mathrm{O}_{2}$ and $\mathrm{O}_{2}{ }^{-}$, were measured in the leaves and roots of $B$. napus under Se stress. Moreover, the roles of MT in alleviating Se-induced oxidative injury were also evaluated (Fig. 2d and e). Considerably more $\mathrm{H}_{2} \mathrm{O}_{2}$ and $\mathrm{O}_{2}{ }^{\cdot-}$ accumulated in the roots than the leaves. Relative to the control, there were 17 and 22\%, 71 and 76\%, and 144 and $168 \%$ increases in $\mathrm{H}_{2} \mathrm{O}_{2}$ and 29 and $20 \%, 68$ and $63 \%$, and 147 and $165 \%$ increases in $\mathrm{O}_{2}{ }^{-}$in the leaves and roots at $50 \mu \mathrm{M}, 100 \mu \mathrm{M}$, and $200 \mu \mathrm{M}$ Se, respectively. Exogenous MT alleviated Se-induced oxidative damage. The strongest MT-mediated reduction in oxidative injury was observed for the $100 \mu \mathrm{M} \mathrm{MT}+50 \mu \mathrm{M}$ Se treatment wherein the leaf and root $\mathrm{H}_{2} \mathrm{O}_{2}$ and $\mathrm{O}_{2}{ }^{\cdot-}$ levels were 24 and $25 \%$ and 19 and $24 \%$ lower, respectively, in comparison with all other $\mathrm{MT}+$ Se treatments. To confirm that ROS $\left(\mathrm{H}_{2} \mathrm{O}_{2}\right.$ and $\left.\mathrm{O}_{2}{ }^{-}\right)$accumulated in the plants under Se stress and that MT attenuated this effect, we stained the roots of B. napus plants with 3,3diaminobenzidine (DAB) and nitro blue tetrazolium (NBT). Compared with the control, the roots of the plants subjected to $200 \mu \mathrm{M}$ Se presented with dark brown $\left(\mathrm{H}_{2} \mathrm{O}_{2}\right)$ and dark blue $\left(\mathrm{O}_{2}{ }^{\cdot-}\right)$ staining (Fig. $2 \mathrm{~g}$ and h). In contrast, MT treatment reduced the intensity of the DAB and NBT staining in B. napus roots exposed to 
SE stress. Furthermore, the application of exogenous MT promoted the biosynthesis of endogenous MT (Additional file 1: Table S1). Exogenous MT $100 \mu \mathrm{M}$ strongly induced endogenous MT accumulation under Se stress.

To investigate the efficacy of exogenous MT at maintaining plasma membrane stability in response to $\mathrm{Se}$ stress, we measured malondialdehyde (MDA) and relative electrolyte leakage (REL) (Fig. 2b and f). Relative to the control, there were no significant changes $(P \geq 0.05)$ in REL or MDA in the standalone Se or MT treatments. However, compared with the control, MDA and REL significantly $(P \leq 0.05)$ increased by 11 and $8 \%, 33$ and $24 \%$, and 75 and $56 \%$ in the leaves and roots and by 24 , 66 , and $142 \%$ in the leaves at $50 \mu \mathrm{M}, 100 \mu \mathrm{M}$, and $200 \mu \mathrm{M}$, respectively. Moreover, exogenous MT suppressed increases in MDA and REL relative to the control and the other MT treatments (Fig. 2b and f).

\section{MT enhances se tolerance by inducing antioxidant} enzymes and regulating phosphate/silicon transporters To examine the efficacy of MT at regulating the ROS-scavenging system under Se stress, we measured superoxide dismutase (SOD), ascorbate peroxidase (APX), glutathione reductase (GR), and catalase (CAT) activity in B. napus leaves and roots (Fig. 3ad). SOD and APX activity increased and CAT and GR activity decreased with increasing Se dose. However, the most significant $(P \leq 0.05)$ alterations in antioxidant enzyme activity were detected at $200 \mu \mathrm{M}$ Se. Exogenous MT further changed the enzyme activity levels under Se stress especially at MT and Se doses of $100 \mu \mathrm{M}$ and $200 \mu \mathrm{M}$, respectively (Fig. 3a-d).

Earlier studies reported that Se (IV) is transportedmainly via phosphate/silicon influx transporters [60, 61]. To evaluate the activity levels of these transporter genes in $B$. napus, we performed an expression analysis on its roots. The gene expression analysis of phosphate and silicon influx transporter (OsPT2 and Lis2) displayed a substantial up-regulation in their gene expressions. The expression of OsPT2 was more abundant and highly expressed than Lis2. These results suggested that OsPT2 more actively participate in selenite uptake in comparison with Lis2 (Fig. 3e). Exogenous MT upregulated both transporter genes but especially Lis 2 at $100 \mu \mathrm{M} \mathrm{MT}+$ $200 \mu \mathrm{M}$ Se (IV) (Fig. 3e).

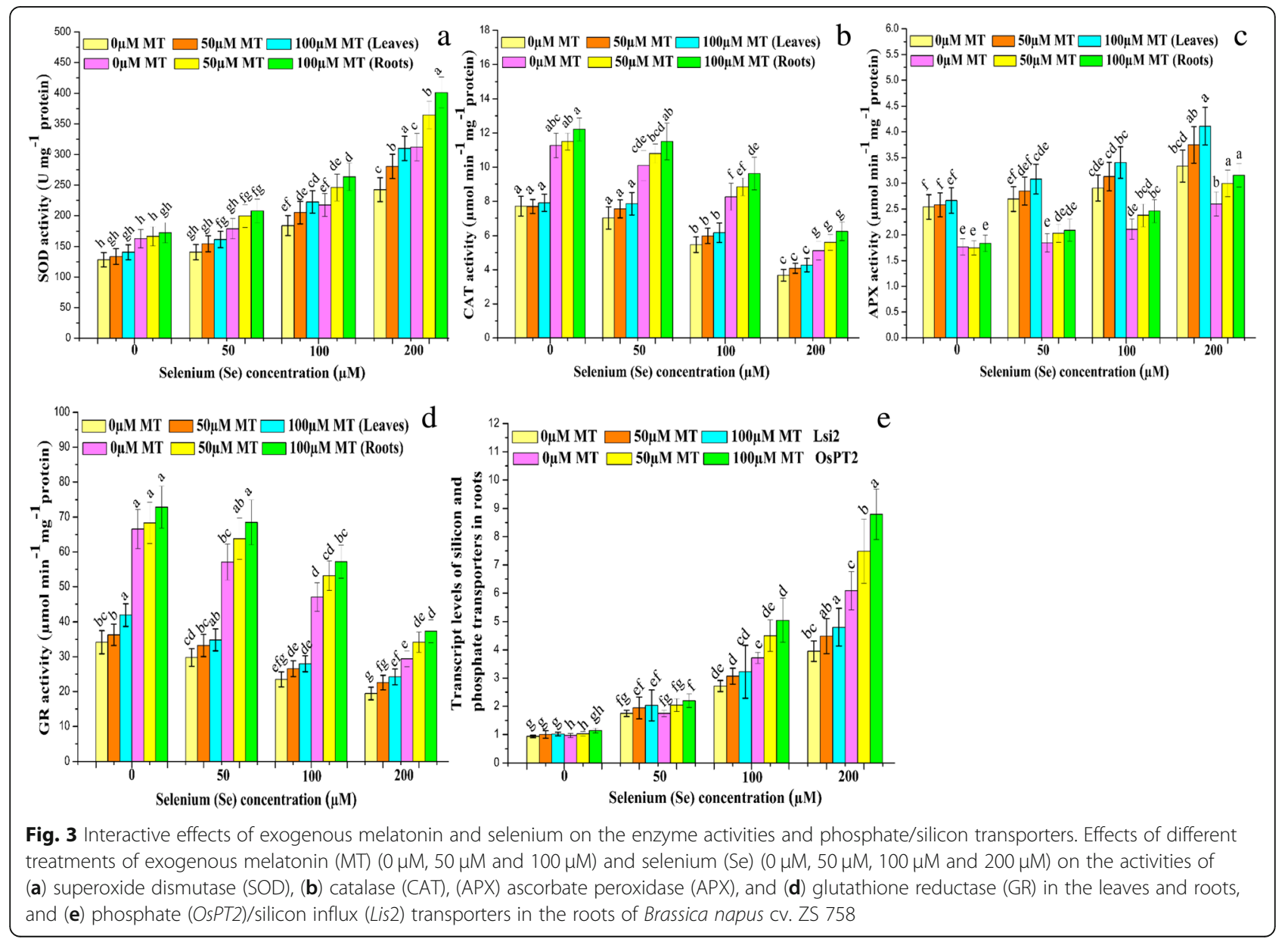




\section{Exogenous MT stimulates se sequestration by inducing endogenous chelating compounds and their metabolic enzymes}

To evaluate the efficacy of MT at inducing chelating agent biosynthesis, we measured the levels of reduced glutathione (GSH), oxidized glutathione (GSSG), nonprotein thiols (NPTs), phytochelatins (PCs), and cysteine in the leaves and roots of B. napus plants under Se stress (Fig. 4a-e). Standalone Se treatments significantly increased all thiols relative to the control. Maximum increases in thiol content were detected for the $200 \mu \mathrm{M}$ Se treatment. Exogenous MT further increased thiol levels under Se stress. Compared with the control, maximum increases in thiol content were observed at $100 \mu \mathrm{M} \mathrm{MT}+50 \mu \mathrm{M}$ Se (37 and 42\%, 19 and 34\%, 16 and 6\%, 26 and 33\%, 20 and 32\%, and 27 and $49 \%$ for GSH, GSSG, GSH/GSSG, NPTs, PCs, and cysteine in the leaves and roots, respectively. To assess the importance of MT in Se detoxification, we measured the enzymes participating in plant thiol metabolism (Fig. 4f-h). Relative to the control, the standalone Se treatment significantly $(P \leq 0.05)$ upregulated gammaglutamylcysteine synthase ( $\gamma$-ECS), glutathione- $S$-transferase (GST), and phytochelatin synthase (PCS) by 53 and $57 \%, 51$ and $85 \%$, and 88 and $57 \%$ in the leaves and roots, respectively. Exogenous MT further raised the levels of these enzymes. The maximum increases at $100 \mu \mathrm{M} \mathrm{MT}+50 \mu \mathrm{M}$ Se were 35 and $36 \%$ ( $\gamma$-ECS), 40 and $58 \%$ (GST), and 47 and 29\% (PCS) in the leaves and roots, respectively, relative to the other $\mathrm{MT}+\mathrm{Se}$ treatments and the standalone Se treatment. The observed increases in thiol metabolism in the $\mathrm{MT}+\mathrm{Se}$ treatments compared with the standalone Se treatment suggested that MT participates in Se detoxification.

\section{Exogenous MT facilitates stomatal opening}

Scanning electron microscopy (SEM) disclosed that stomatal length and width were smaller in the leaves of $B$.

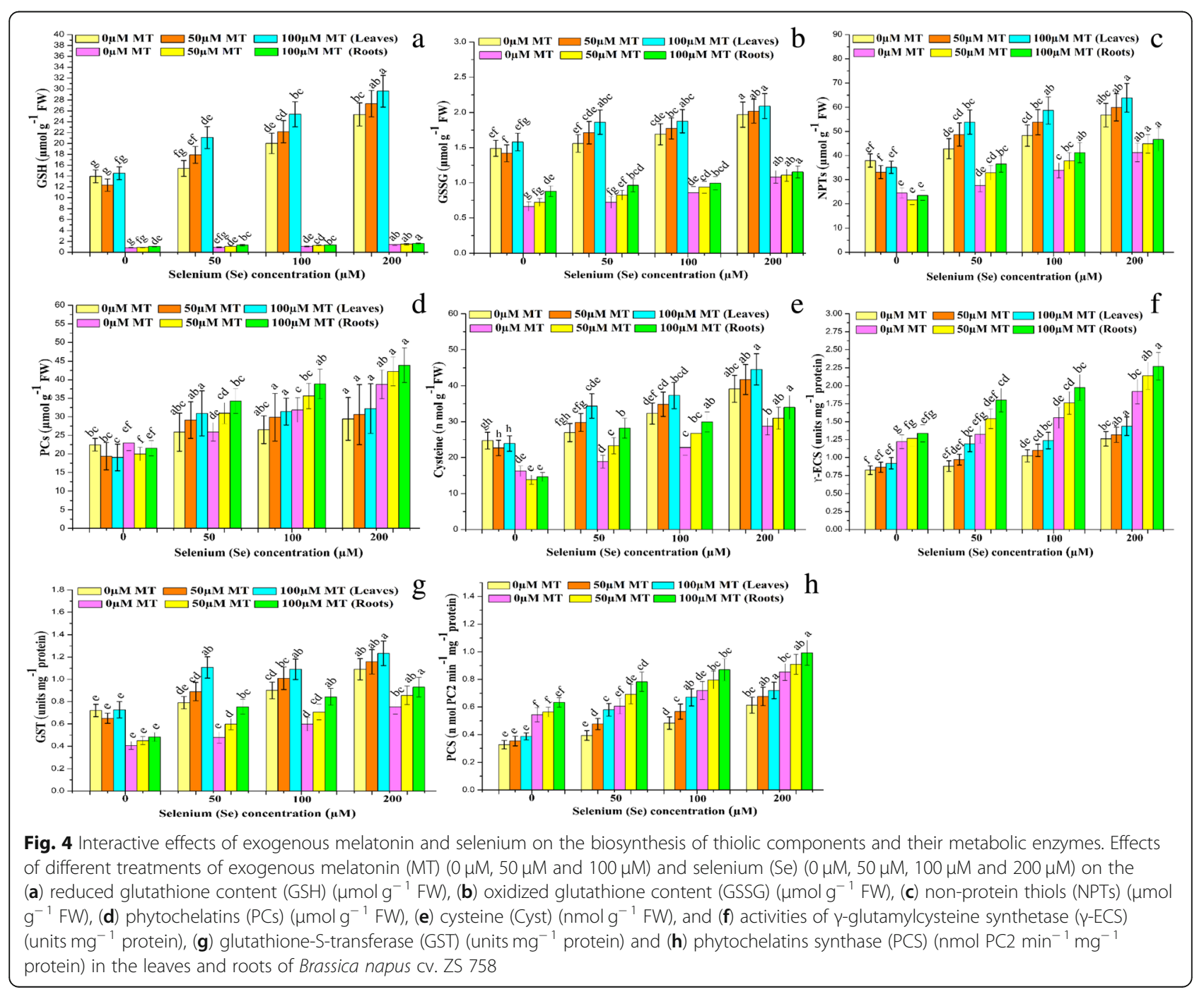


napus subjected to Se stress than those of the control. However, Se exposure had no apparent effect on stomatal movement (Fig. 5a-e). The stomata of B. napus leaves treated with exogenous MT were longer, wider, and more open than those of $B$. napus plants subjected to Se stress alone. MT may facilitate stomatal opening by osmotically retaining water in the leaves. Interactions among the levels of selenium, melatonin, and all aforementioned parameters were evaluated by two-way ANOVA and a $\beta$-regression model (Additional file 1: Tables S3-S10).

\section{Discussion}

Selenium (Se) phytotoxicity is a major concern for agricultural scientists [9-11]. As sessile organisms, plants have developed multifaceted strategies to contend with various stressors. Recently, certain researchers and scientists have investigated the use of the growth regulator melatonin (MT) to increase plant resistance to cold [20], salt [21], drought [22], and cadmium [23] stress.

The efficacy of exogenous MT against plant stress depends upon the mode of application (pretreatment/foliar spray/nutrient solution), dosage, stressor, and plant species. It was reported that foliar MT spray $(25 \mu \mathrm{M}$,
$50 \mu \mathrm{M}$, and $100 \mu \mathrm{M})$ against $\mathrm{Cd}$ stress $(25 \mu \mathrm{M}$ and $100 \mu \mathrm{M})$ enhanced plant growth and antioxidant systems by inhibiting $\mathrm{Cd}$ accumulation [12]. However, MT seed soak/root immersion/foliar spray $(20 \mu \mathrm{M}$ and $100 \mu \mathrm{M})$ reduced cold-induced oxidative damage by upregulating the enzymatic/non-enzymatic antioxidant systems [62]. Exogenous MT applied as a nutrient solution $(50 \mu \mathrm{M}$ and $200 \mu \mathrm{M})$ improved growth, biomass, and the antioxidant systems of Cyphomandra betacea [34] and wheat seedlings [63] under Cd stress.

The results of this study showed that exogenously applied Se increases endogenous MT in plant tissues (Additional file 1: Table S1). This finding corroborated those of earlier reports in which Se pretreatment induced endogenous MT while exogenous MT + Se application reduced growth retardation and photoinhibition in tomato plants [36]. Se-induced MT biosynthesis may promote Se tolerance in B. napus. The observed increases in MT content with Se level indicate that MT biosynthesis could be induced by oxidative stress and/or other associated mechanisms. Here, exogenous MT induced de novo endogenous MT production (Additional file 1: Table S1) as it did in rice [64] and wheat [63]. Thus, exogenous MT increased the endogenous MT content and may regulate the
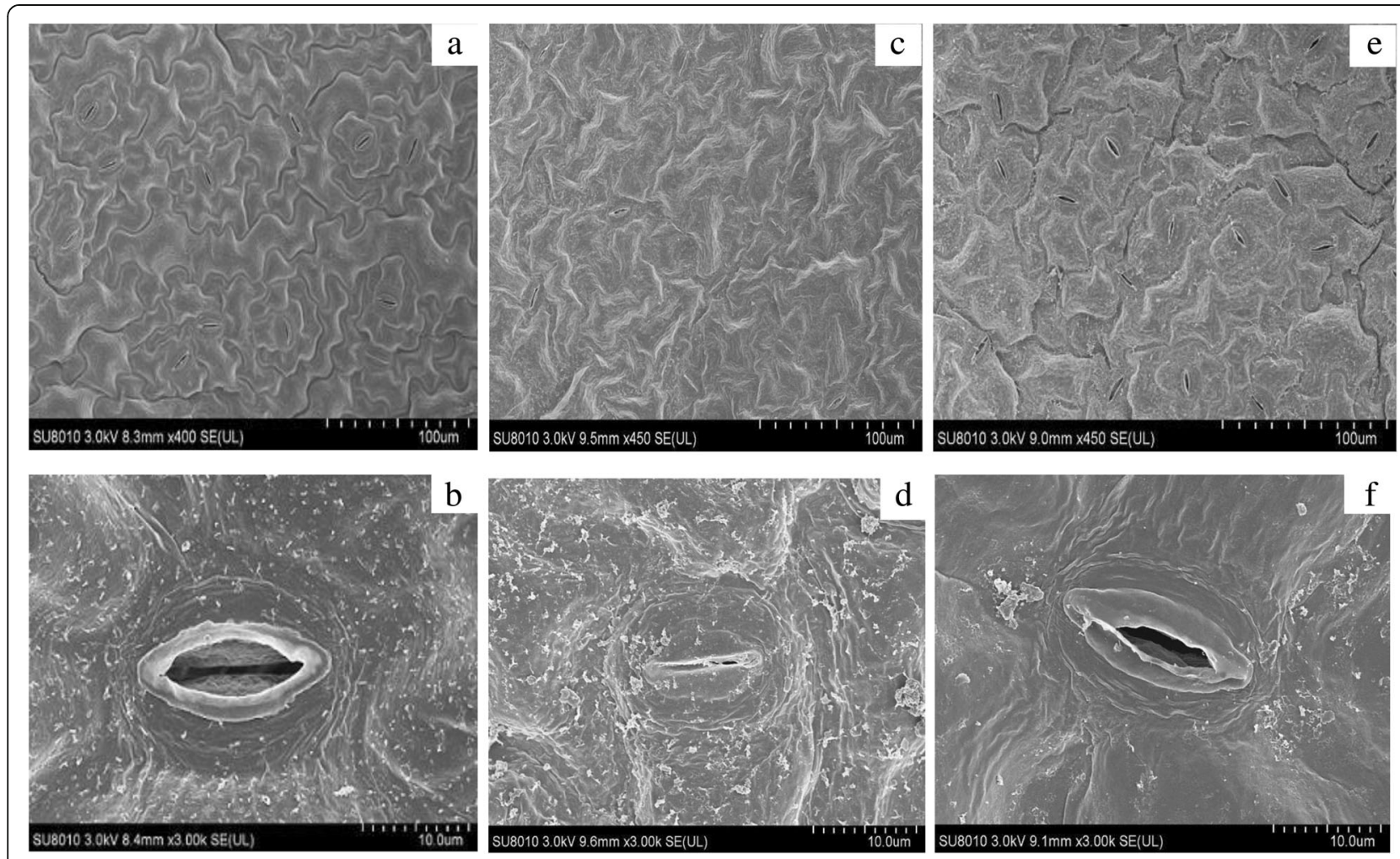

Fig. 5 Interactive effects of exogenous melatonin and selenium on stomatal opening. Scanning electron microscope (SEM) images of stomata showed the responses of exogenous MT on the stomatal aperture of Brassica napus leaves under Se stress. $\mathbf{a}$ and $\mathbf{b}$ showing full opening of leaves stomata under no stress conditions. $\mathbf{c}$ and $\mathbf{d}$ showed the complete closure of leaves stomata under maximum Se $(200 \mu \mathrm{M})$ stress conditions. e and $\mathbf{f}$ illustrated the maximum stomatal opening at $50 \mu \mathrm{M} \mathrm{Se}+100 \mu \mathrm{M}$ MT than other Se + MT treatments 
antioxidant system and restrict ROS generation. In turn, de novo endogenous MT production in B. napus may help alleviate Se phytotoxicity by mitigating Se-induced oxidative damage.

Plant biomass decreased with increasing Se dosage. Exogenous MT recovered the reduction in biomass accumulation caused by Se stress (Table 1). Se-induced declines in plant growth and biomass accumulation were observed in rice [9] possibly as a result of chlorophyll damage and protein synthesis inhibition. Exogenous MT $(50 \mu \mathrm{M}$ and $100 \mu \mathrm{M})$ alleviated Cd stress and promoted growth and biomass formation in Cyphomandra betacea [4] and wheat [60], respectively. In the present study, MT attenuated Se-induced chlorophyll degradation and improved photosynthetic efficiency under both nonstress and Se-stress conditions (Fig. 1a-f). Previous reports revealed that MT repressed chlorophyll degradation and enhanced photosynthetic efficiency in cucumber [65], wheat [66], gardenia [67], and tomato [12, 68] under water, heat, low-light, cadmium, and cold stresses, respectively. MT might maintain chlorophyll and carotenoid levels by scavenging excessive ROS [12]. The declines in net photosynthetic rate and photochemical efficiency $(F v / F m)$ under Se stress (Fig. 1e and f) caused photoinhibition. Therefore, stress-induced ROS production reduces PSII photochemical efficiency by interrupting the electron transport chain (ETC) [69]. In contrast, exogenous MT significantly alleviated photoinhibition and increased photosynthetic efficiency via biostimulant pathways that enhanced PSII photochemical efficiency [70]. Exogenous MT application restrained the decline in PSII efficiency in response to Se stress by making the maximum amount of light energy available to the photosynthetic ETC. Se-induced reduction in the photosynthetic rate may trigger stomatal closing (Fig. 5a-f). Deformation of the guard cells may be caused by inhibition of the metabolic reactions maintaining guard cell turgor. MT increased stomatal length and width by keeping the water potential (Fig. 2b) and proline (Fig. 2c) levels high, thereby opening the stomata (Fig. 5e and f). MT maintained cell turgor, increased proline levels, and opened stomata under drought stress [71]. In the present study, exogenous MT effectively recovered the Se-induced decline in the water-holding capacity of $B$. napus leaves (Fig. 2b). Previous reports demonstrated that exogenous MT mitigated water losses in wheat [72] and maize [73] under salt stress. In tomato leaves under drought conditions, MT recovered foliar water losses by promoting an increase in cuticular wax thickness [74]. Therefore, MT may protect plants against water stress by elevating foliar water potential, minimizing water losses, and maintaining plant metabolism.

Proline, sugars, and free amino acids are biocompatible solutes that protect plants against stress conditions by osmoregulation, ROS scavenging, and plasma membrane integrity maintenance [75]. Here, exogenous MT increased the Se-induced rises in the proline and free amino acid levels and recovered the reduction in soluble sugar content (Fig. 3a-c). Plants usually restore osmotic equilibrium by accumulating excess osmolytes such as proline [76]. The observed increases in proline level in Se-stressed plants treated with exogenous MT (Fig. 2b) reflect the ability of $B$. napus leaves to contend with oxidative damage [77]. Compatible solutes scavenge excess ROS. Exogenous MT increased the proline content in gardenia plants under dark-induced stress [67]. Under plant stress, then, MT may regulate proline metabolism via antioxidant mechanisms. The observed decline in sugar accumulation in plants under Se stress (Fig. 2a) may be explained by protein deformation resulting from the substitution of selenium for sulfur in S-containing proteins such as cysteine and methionine [78]. MT may have effectively repaired this damage (Fig. 2b). It was recently shown that MT recovered protein damage in $B$. napus leaves under salt stress by increasing their soluble sugar content [79]. The additional increases in free amino acids in response to MT application to plants subjected to Se stress (Fig. 2c) suggests that MT induced protein hydrolysis and osmotic adjustments under these conditions. It was also indicated that the application of the growth regulator 5-aminolevulinic acid (5-ALA) adjusts plant metabolism by inducing foliar free amino acid accumulation in B. napus and maintaining or restoring protein structural integrity [80]. The observed marked increases in electrolyte leakage, $\mathrm{H}_{2} \mathrm{O}_{2}$ and $\mathrm{O}_{2}{ }^{--}$, and MDA in B. napus under Se stress (Fig. 2b, d-f) caused severe oxidative damage and lipid peroxidation and the loss of plasma membrane integrity. Exogenous MT reversed Se-induced oxidative damage by reducing ROS and MDA content and decreasing electrolyte leakage.

Previous studies disclosed that exogenous MT maintained oxidative homeostasis by reducing ROS and MDA accumulation as well as electrolyte leakage in tomato [62] and rice [64] subjected to cold stress. Earlier reports demonstrated that exogenous MT activates antioxidant enzymes and promotes the accumulation of non-enzymatic antioxidants to offset damage caused by environmental stressors [22, 63]. Exogenous MT upregulated SOD, APX, GR, and CAT which, in turn, scavenged the excess ROS produced under Se stress (Fig. 3a-d). Therefore, exogenous MT may act as signaling molecule that induces the antioxidant defense system and diminishes the Se-induced oxidative damages.

Previous studies documented that Se is either transported by sulfate or phosphate transporter genes [6, 40, 41]. In current study, selenite was suggested to be mediated mainly by phosphate transporters rather than silicon 


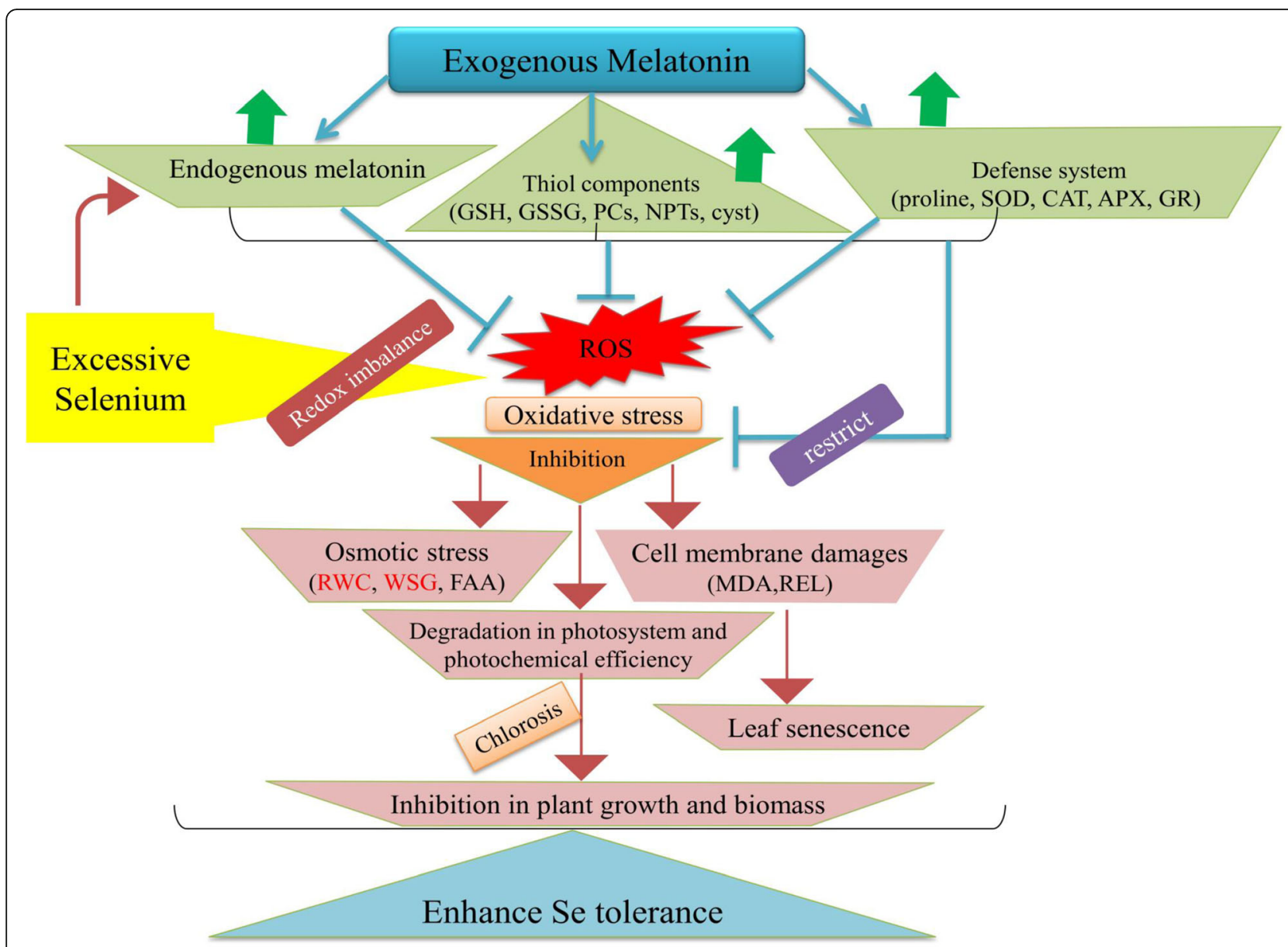

Fig. 6 Summary of protective mechanisms of melatonin against selenium phytotoxicity. A schematic diagram showed the mitigating effects of exogenous MT on Brassica napus L. seedlings under Se (IV) stress. Se heightened its toxicity by (I) Over-accumulating ROS that leads to chlorophyll degradation and ultimately growth reduction. (II) Induction of electrolyte leakage and lipid peroxidation reflects the damages in cellular membrane. (III) Disturbances in the synchronization of the defense system by increasing SOD and APX activities, proline, and free amino acids but declined the key enzymes (CAT and GR) and soluble sugar. (IV) Osmotic stress by lowering relative water and sugar contents. (V) An increase in the levels of thiol compounds (GSH, GSSG, NPTs, cysteine, and PCs) depicted the greater potential of Brassica napus plants to confer Se tolerance. Exogenous MT ameliorated the Se toxicity by enhancing photochemical efficiency and osmo-protection, which is linked with the enhanced plant growth and biomass production. In addition, exogenous MT induced the endogenous MT content which assist in the protective role of MT against Se-prompted ROS generation by inducing enzymes involved in AsA-GSH cycle (APX and GR), ROS-detoxifying enzymes (mainly SOD and CAT), biosynthesis of thiol components (especially GSH and phytochelatins), and the enzymes involved in thiol metabolism (Y-ECS, GST and PCS). The greater accumulation of MT and thiol components in roots suggested roots as greater site for the detoxification of Se as compared with leaves. Diagram indicates $\mathrm{O}_{2}{ }^{-}$ (superoxide), $\mathrm{H}_{2} \mathrm{O}_{2}$ (hydrogen peroxide), SOD (superoxide dismutase), CAT (catalase), APX (ascorbate peroxidase), GR (glutathione reductase), GSH (reduced glutathione), GSSG (oxidized glutathione), RWC (relative water content), Pro (proline), WSG (water soluble sugar), FAA (free amino acids), REL (relative electrolyte leakage), MDA (melondialdehyde), NPTs (non-protein thiols), PCs (phytochelatins), cyst (cysteine), $\gamma$-ECS (gamma-glutamylcysteine synthase), GST (glutathione-S-transferase) and PCS (phytochelatins synthase)

influx transporters (Fig. 3e) which revealed the key role of phosphate transport pathway in the uptake of selenite. Although further convincing molecular evidence is required to support this investigation. This hypothesis was strongly supported by previous results that selenite uptake was more pronounced in both wild type and mutant plants under phosphate-deficient conditions which resulted in the activation of phosphate transporters to enhance the phosphate uptake. And, concluded that phosphate transporters are directly involved in selenite uptake $[6,40]$.
Various enzymatic pathways synthesize phytochelatins from GSH via metal and metalloid ion chelation [81]. The thiols cysteine, GSH, GSSG, NPTs, and PCs participate in metalloid detoxification [82]. The present study revealed that plants under Se stress accumulate comparatively high levels of thiols. Moreover, exogenous MT further increases plant thiol levels (Fig. 4a-e). Thus, plants attempt to detoxify Se by increasing thiol content. MT-induced thiol biosynthesis sequestered and detoxified Cd in tomato [12]. Here, MT enhanced GR activity 
(Fig. 3d) and increased the GSH:GSSG ratio (Additional file 1: Table S3) in B. napus. These effects could induce $\gamma$-ECS (Fig. 4f). The observed increase in GSH (Fig. 4a) caused by MT may increase $\gamma$-ECS activity which, in turn, delays leaf senescence (Fig. 4f). These responses were also reported for apple trees [70]. In another study, exogenous MT upregulated SIGSH1 and SIPCS in tomato leaves. These genes encode GSH and PCs, respectively [12]. The thiol-metabolizing enzymes $\gamma$-ECS, GST, and PCS participated mostly in GSH biosynthesis and conjugation, respectively [83]. Here, thiol-metabolizing enzymes were induced in response to plant Se exposure possibly in the attempt to detoxify it. MT further augmented this mechanism (Fig. 4f-h). The observed upregulation of thiol-metabolizing enzymes in response to de novo thiol biosynthesis induced by Se exposure was accompanied by an increase in NPTs (mainly GSH and PCs) (Fig. 4a, c, and d). Previous studies stated that arsenic (As) stress upregulated thiol-metabolizing enzymes as well as NPTs [14]. Here, relative to the standalone Se treatment, the $\mathrm{MT}+\mathrm{Se}$ treatments induced greater accumulations of cysteine (Fig. 4e) and GSH (Fig. 4a). This response may enable plants to increase sulfur metabolism and mediate thiol metabolism for Se detoxification. Elevated cysteine and GSH levels could improve sulfur metabolism which, in turn, may detoxify arsenic [84]. The relatively higher levels of thiols in plants under the MT + Se treatment than in those exposed to Se alone indicate that MT is very effective at Se detoxification. The comparatively greater accumulation of chelating compounds such as PCs in the roots suggested that these organs are major brunt of Se detoxification. In addition, the augmented thiols accumulation in roots than leaves of MT-treated B. napus suggests that MT more effectively sequesters Se in the roots and lowers its mobility so that it is not readily translocated to the leaves (Additional file 1: Table S1). Previous studies proposed that MT may prevent $\mathrm{Cd}$ translocation from root to leaf possibly by enhancing de novo thiol biosynthesis [12].

\section{Conclusions}

Based on our findings, a schematic diagram was plotted to highlight the Se-induced toxic effects in Brassica napus plants mitigated by exogenous MT (Fig. 6). Here, we confirmed that high Se concentrations reduced plant growth and biomass production, impaired PSII photochemical efficiency $(F v / F m)$, decreased $C h l a, C h l b$, and carotenoid levels, lowered the net photosynthetic rate, increased osmotic stress by decreasing RWC, and altered stomata size and shape. Selenium also destroyed plasma membrane integrity by promoting lipid peroxidation and oxidative damage. These effects were reflected in the observed increases in REL, MDA, $\mathrm{H}_{2} \mathrm{O}_{2}$, and $\mathrm{O}_{2}{ }^{--}$levels. Elevated Se perturbed the plant antioxidant system by enhancing SOD and APX activity and increasing proline and FAA levels and chelator biosynthesis. However, reduced the CAT and GR activity and soluble sugar concentrations. Coapplication of exogenous MT and excess Se induced de novo endogenous MT production. MT also increased antioxidant enzyme activity, scavenged excess ROS, improved photosynthetic capacity, restored water levels, and protected plasma membranes against lipid peroxidation. Exogenous MT increased RWC, decreased photoinhibition, and lowered the REL and MDA levels. Thus, exogenous MT enhances plant growth and biomass accumulation under Se stress. It also augmented plant oxidative stress defense and Se detoxification by inducing the antioxidant system and enhancing the Se binding capacity of GSH, GSSG, NPTs, PCs, and cysteine. In the present study, $100 \mu \mathrm{M}$ exogenous MT was the most efficacious dose for protecting $B$. napus plants against the toxic effects of Se. Our findings demonstrate that exogenous MT improves Se tolerance and minimized the Seaccumulation in B. napus plants. These findings provide implications in understanding the effect of plant MT and develop strategies for safe food production in Se-enriched soils. However, the molecular mechanisms, genetic evidences and signaling pathways by which exogenous MT mediates Se detoxification and induces MT biosynthesis merit further exploration. Further studies are recommended in soil-based environment by using other application methods (foliar spray and seed priming with MT) to reveal the possible plant-protection against other environmental pollutants such as cobalt, beryllium, nickel, and strontium. Our future study will be focused on the identification of molecular networks of MT in the regulation of abiotic stresses in B. napus.

\section{Supplementary information}

Supplementary information accompanies this paper at https://doi.org/10. 1186/s12870-019-2110-6.

Additional file 1: Table S1. Effects of exogenous melatonin (MT) $(0 \mu \mathrm{M}$ $50 \mu \mathrm{M}$ and $100 \mu \mathrm{M})$ and selenium (Se) $(0 \mu \mathrm{M}, 50 \mu \mathrm{M}, 100 \mu \mathrm{M}$, and $200 \mu \mathrm{M})$ treatments on the endogenous MT and Se contents in the leaves and roots of Brassica napus CV. ZS 758. Table S2. Oligonucleotide primer sequences, used for qRT-PCR analysis. Table S3. Effects of different treatments of melatonin (MT) $(0 \mu \mathrm{M}, 50 \mu \mathrm{M}$ and $100 \mu \mathrm{M})$ and selenium (Se) $(0 \mu \mathrm{M}, 50 \mu \mathrm{M}, 100 \mu \mathrm{M}$, and $200 \mu \mathrm{M})$ on the ratio of GSH/GSSG ( $\mu \mathrm{M} / \mathrm{g} \mathrm{FW})$ in the leaves and roots of Brassica napus CV. ZS 758. Table S4. Two-way ANOVA and multiple regression model for the morphological traits of Brassica napus CV. ZS 758. Table S5. Two-way ANOVA and multiple regression model for the photosynthesis traits of Brassica napus CV. ZS 758 . Table S6. Two-way ANOVA and multiple regression model for the osmotic metabolites in the leaves of Brassica napus cv. ZS 758. Table S7. Two-way ANOVA and multiple regression model for the reactive oxygen species (ROS) and malondialdehyde (MDA) contents in the leaves and roots of Brassica napus cv. ZS 758. Table S8. Two-way ANOVA and multiple regression model for the antioxidant enzymes $\left(\mu \mathrm{mol} \mathrm{minr}^{-1} \mathrm{mg}^{-1}\right.$ protein) in the leaves and roots of Brassica napus Cv. ZS 758. Table S9. Two-way ANOVA and regression analysis for the thiol components in the 
leaves ( $L$ ) and roots (R) of Brassica napus cv. ZS 758. Table S10. Two-way ANOVA and regression analysis for the thiolic ligands related metabolic enzymes and endogenous selenium (Se) contents in the leaves $(\mathrm{L})$ and roots (R) of Brassica napus cv. ZS 758.

\section{Abbreviations}

APX: Ascorbate peroxidase; CAT: Catalase; cyst: cysteine; FAA: Free amino acids; GR: Glutathione reductase; GSH: Reduced glutathione; GSSG: Oxidized glutathione; GST: Glutathione-S-transferase; $\mathrm{H}_{2} \mathrm{O}_{2}$ : Hydrogen peroxide; MDA: Melondialdehyde; NPTs: Non-protein thiols; $\mathrm{O}_{2}$ : Superoxide radical; PCs: Phytochelatins; PCS: Phytochelatins synthase; Pro: Proline; REL: Relative electrolyte leakage; RWC: Relative water content; SOD: Superoxide dismutase; WSG: Water-soluble sugar; $\gamma$-ECS: Gamma-glutamylcysteine synthase

\section{Acknowledgments}

We thank Nianhang Rong and Junying Li from the Center of Analysis \& Measurement, Zhejiang University for their assistance during the Scanning Electron Microscopic (SEM) analysis.

\section{Authors' contributions}

$Z U$ is the first and main author. RAG, SA and WZ designed the experiment. $\mathrm{QH}, \mathrm{SA}, \mathrm{RAG}$, and TMM analyze and interpret the data. SA, RAG, BA, FH and WZ helps in drafting of the article. BA, RAG and WJ critically revised the manuscript. All authors read and approved the final manuscript.

\section{Funding}

This work was supported by the National Key Research and Development Program (2018YFD0100601), the National Natural Science Foundation of China (31650110476), the Jiangsu Collaborative Innovation Center for Modern Crop Production, the Sino-German Research Project (GZ 1362), the Science and Technology Department of Zhejiang Province (2016C02050-8, LGN18C130007), and the Agricultural Technology Extension Funds of Zhejiang University.

\section{Availability of data and materials}

The datasets used and/or analyzed during the current study available from the corresponding author on reasonable request.

\section{Ethics approval and consent to participate}

Not applicable

\section{Consent for publication}

Not applicable

\section{Competing interests}

"All authors declared that they have no competing interest regarding the submission of this article and its probable publication".

\section{Author details}

${ }^{1}$ Institute of Crop Science, Ministry of Agriculture and Rural Affairs Key Laboratory of Spectroscopy Sensing, Zhejiang University, Hangzhou 310058, China. ${ }^{2}$ Oil Crops Research Institute, Chinese Academy of Agricultural Sciences, Wuhan 430062, China. ${ }^{3}$ Department of Agronomy, University of Agriculture, Faisalabad 38040, Pakistan. ${ }^{4}$ Lab of Systematic \& Evolutionary Botany and Biodiversity, College of Life Science, Zhejiang University, Hangzhou 310058, China.

Received: 2 July 2019 Accepted: 31 October 2019

Published online: 21 November 2019

\section{References}

1. Shahid M, Niazi NK, Khalid S, Murtaza B, Bibi I, Rashid MI. A critical review of selenium biogeochemical behavior in soil-plant system with an inference to human health. Environ Pollut. 2018;234:915-34.

2. Drahonovský J, Szkova J, Mestek O, Tremlova J, Kana A, Najmanova J, Tlustos P. Selenium uptake, transformation and inter-element interactions by selected wildlife plant species after foliar selenate application. Environ Exp Bot. 2016;125:12-9.
3. Chen Y, Mo HZ, Hu LB, Li YQ, Chen J, Yang LF. The endogenous nitric oxide mediates selenium-induced phytotoxicity by promoting ROS generation in brassica rapa. PLoS One. 2014;9:1-11.

4. Winkel LHE, Vriens B, Jones GD, Schneider LS, Pilon-Smits E, Banuelos GS. Selenium cycling across soil-plant-atmosphere interfaces: a critical review. Nutrients. 2015;7:4199-239.

5. Zhu YG, Pilon-Smits EAH, Zhao FJ, Williams PN, Meharg AA. Selenium in higher plants: understanding mechanisms for biofortification and phytoremediation. Trends Plant Sci. 2009;14:436-42.

6. Li HF, McGrath SP, Zhao FJ. Selenium uptake, translocation and speciation in wheat supplied with selenate or selenite. New Phytol. 2008;178:92-102.

7. Hopper $J$ L, Parker DR. Plant availability of selenite and selenate as influenced by the competing ions phosphate and sulfate. Plant Soil. 1999; 210:199-207.

8. Ribeiro DM, Silva Júnior DD, Cardoso FB, Martins AO, Silva WA, Nascimento VL, Araújo WL. Growth inhibition by selenium is associated with changes in primary metabolism and nutrient levels in Arabidopsis thaliana. Plant Cell Environ. 2016;39:2235-46.

9. Mostofa MG, Hossain MA, Siddiqui MN, Fujita M, Tran LSP. Phenotypical, physiological and biochemical analyses provide insight into se-induced phytotoxicity in rice plants. Chemosphere. 2017;178:212-23.

10. Ulhassan Z, Ali S, Gill RA, Mwamba TM, Abid M, Li L, Zhang N, Zhou W. Comparative orchestrating response of four oilseed rape (Brassica napus) cultivars against the selenium stress as revealed by physio-chemical, ultrastructural and molecular profiling. Ecotoxicol Environ Saf. 2018;161:634-47.

11. Ulhassan Z, Gill RA, Ali S, Mwamba TM, Ali B, Wang J, Huang Q, Aziz R, Zhou W. Dual behavior of selenium: insights into physio-biochemical, anatomical and molecular analyses of four Brassica napus cultivars. Chemosphere. 2019;225:329-41.

12. Hasan M, Ahammed GJ, Yin L, Shi K, Xia X, Zhou Y, Yu J, Zhou J. Melatonin mitigates cadmium phytotoxicity through modulation of phytochelatins biosynthesis, vacuolar sequestration, and antioxidant potential in Solanum lycopersicum L. Front Plant Sci. 2015;6:601.

13. Naz FS, Yusuf M, Khan TA, Fariduddin Q, Ahmad A. Low level of selenium increases the efficacy of 24-epibrassinolide through altered physiological and biochemical traits of Brassica juncea plants. Food Chem. 2015;185:441-8.

14. Kumar A, Dixit G, Singh AP, Dwivedi S, Srivastava S, Mishra K, Tripathi RD. Selenate mitigates arsenite toxicity in rice (Oryza sativa L.) by reducing arsenic uptake and ameliorates amino acid content and thiol metabolism. Ecotoxicol Environ Saf. 2016;33:350-9.

15. Kanwar MK, Yu J, Zhou J. Phytomelatonin: recent advances and future prospects. J Pineal Res. 2018;65:1-35.

16. Dubbels R, Reiter RJ, Klenke E, Goebel A, Schnakenberg E, Ehlers C, Schiwara HW, Schloot W. Melatonin in edible plants identified by radioimmunoassay and by high performance liquid chromatography-mass spectrometry. J Pineal Res. 1995;18:28-31.

17. Zhang N, Sun Q, Zhang H, Cao Y, Weeda S, Ren S, Guo YD. Roles of melatonin in abiotic stress resistance in plants. J Exp Bot. 2015;66:647-56.

18. Wei W, Li QT, Chu YN, Reiter RJ, Yu XM, Zhu DH, Zhang WK, Ma B, Lin Q, Zhang JS, Chen SY. Melatonin enhances plant growth and abiotic stress tolerance in soybean plants. J Exp Bot. 2014;66:695-707.

19. Qi ZY, Wang KX, Yan MY, Kanwar M, Li DY, Wijaya L, Alyemeni M, Ahmad P, Zhou J. Melatonin alleviates high temperature-induced pollen abortion in Solanum lycopersicum. Molecules. 2018;23:386.

20. Li X, Wei JP, Scott ER, Liu JW, Guo S, Li Y, Zhang L, Han WY. Exogenous melatonin alleviates cold stress by promoting antioxidant defense and redox homeostasis in camellia sinensis L. Molecules. 2018;23:1-13.

21. Ke Q, Ye J, Wang B, Ren J, Yin L, Deng X, Wang S. 2018. Melatonin mitigates salt stress in wheat seedlings by modulating polyamine metabolism. Front Plant Sci. 2018;9:1-11.

22. Li J, Zeng L, Cheng Y, Lu G, Fu G, Ma H, Liu Q, Zhang X, Zou X, Li C. Exogenous melatonin alleviates damage from drought stress in Brassica napus L. (rapeseed) seedlings. Act Physiol Plant. 2018;40:1-11.

23. Kaya C, Okant M, Ugurlar F, Alyemeni MN, Ashraf M, Ahmad P. Melatoninmediated nitric oxide improves tolerance to cadmium toxicity by reducing oxidative stress in wheat plants. Chemosphere. 2019;225:627-38.

24. Manchester LC, Coto-Montes A, Boga JA, Andersen LPH, Zhou Z, Galano A, Vriend J, Tan DX, Reiter RJ. Melatonin: an ancient molecule that makes oxygen metabolically tolerable. J Pineal Res. 2015:59:403-19.

25. Bałabusta M, Szafranska K, Posmyk MM. Exogenous'melatonin improves antioxidant defense in cucumber seeds (Cucumis sativus L.) germinated under chilling stress. Front Plant Sci. 2016;7:1-12. 
26. Gill RA, Zang L, Ali B, Faroog MA, Cui P, Yang S, Ali S, Zhou W. Chromiuminduced physio-chemical and ultrastructural changes in four cultivars of Brassica napus L. Chemosphere. 2015a;120:154-64.

27. Gill RA, Ali B, Cui P, Shen E, Faroog MA, Islam F, Ali S, Mao B, Zhou W. Comparative transcriptome profiling of two Brassica napus cultivars under chromium toxicity and its alleviation by reduced glutathione. BMC Genomics. 2016;17:1-25.

28. Gill RA, Ali B, Yang S, Tong C, Islam F, Gill MB, Mwamba TM, Ali S, Mao B, Liu S, Zhou W. Reduced glutathione mediates pheno-ultrastructure, kinome and transportome in chromium-induced Brassica napus L. Front Plant Sci. 2017;8:1-24.

29. Ali B, Qian P, Jin R, Ali S, Khan M, Aziz R, Tian T, Zhou WJ. Physiological and ultra-structural changes in Brassica napus seedlings induced by cadmium stress. Biol Plant. 2014a;58:131-8.

30. Mwamba TM, Li L, Gill RA, Islam F, Nawaz A, Ali B, Farooq MA, Lwalaba JL, Zhou W. Differential subcellular distribution and chemical forms of cadmium and copper in Brassica napus. Ecotoxicol Environ Saf. 2016;134: 239-49.

31. Ali S, Gill RA, Mwamba TM, Zhang N, Lv MT, UlHassan Z, Islam F, Zhou WJ. Differential cobalt-induced effects on plant growth, ultrastructural modifications, and antioxidative response among four Brassica napus L. cultivars. Int J Environ Sci Tech. 2017;15:1-16.

32. Ali S, Gill RA, Ulhassan Z, Najeeb U, Kanwar MK, Abid M, Mwamba TM, Huang Q, Zhou WJ. Insights on the responses of Brassica napus cultivars against the cobalt-stress as revealed by carbon assimilation, anatomical changes, and secondary metabolites. Environ Exp Bot. 2018;156:183-96.

33. Ali S, Jin R, Gill RA, Mwamba TM, Zhang N, Ulhassan Z, Islam F, Ali S, Zhou WJ. Beryllium stress-induced modifications in antioxidant machinery and plant ultrastructure in the seedlings of black and yellow seeded oilseed rape. Biomed Res Int. 2018:1-14.

34. Lin L, Li J, Chen F, Liao MA, Tang Y, Liang D, Xia H, Lai Y, Wang X, Chen C, Ren $W$. Effects of melatonin on the growth and cadmium characteristics of cyphomandra betacea seedlings. Environ Monit Assess. 2018;190:1-8.

35. Tang $Y$, Lin L, Xie Y, Liu J, Sun G, Li H, Liao MA, Wang Z, Liang D, Xia H, Wang $X$. Melatonin affects the growth and cadmium accumulation of Malachium aquaticum and Galinsoga parviflora. Int J Phytoremediation. 2018;20:295-300.

36. Li MQ, Hasan MK, Li CX, Ahammed GJ, Xia XJ, Shi K, Zhou YH, Reiter RJ, Yu JQ, Xu MX, Zhou J. Melatonin mediates selenium-induced tolerance to cadmium stress in tomato plants. J Pineal Res. 2016;61:291-302.

37. Gill RA, Hu XQ, Ali B, Yang C, Shou JY, Wu YY, Zhou WJ. Genotypic variation of the responses to chromium toxicity in four oilseed rape cultivars. Biol Plant. 2014:58:539-50.

38. Gill RA, Ali B, Islam F, Faroog MA, Gill MB, Mwamba TM, Zhou W. Physiological and molecular analyses of black and yellow seeded Brassica napus regulated by 5-aminolivulinic acid under chromium stress. Plant Physiol Biochem. 2015b;94:130-43.

39. Arnon DI, Hoagland DR. Crop production in artificial solution with special reference to factors affecting yield and absorption of inorganic nutrients. Soil Sci. 1940;50:463-85.

40. Zhang L, Hu B, Li W, Che R, Deng K, Li H, Yu F, Ling H, Li Y, Chu C. OsPT2, a phosphate transporter, is involved in the active uptake of selenite in rice. New Phytol. 2014;201:1183-91.

41. Zhao XQ, Mitani N, Yamaji N, Shen RF, Ma JF. Involvement of silicon influx transporter OsNIP2; 1 in selenite uptake in rice. Plant Physiol. 2010;1 10:1871-7.

42. Momoh EJJ, Zhou WJ. Growth and yield responses to plant density and stage of transplanting in winter oilseed rape (Brassica napus L.). J Agron Crop Sci. 2001;186:253-9.

43. Kohli SK, Bali S, Tejpal R, Bhalla V, Verma V, Bhardwaj R, Alqarawi AA, Abd_ Allah EF, Ahmad P. In-situ localization and biochemical analysis of biomolecules reveals Pb-stress amelioration in Brassica juncea L. by coapplication of 24-Epibrassinolide and Salicylic Acid. Scient Rep. 2019;9:3524.

44. Ahanger MA, Ashraf M, Bajguz A, Ahmad P. Brassinosteroids regulate growth in plants under stressful environments and crosstalk with other potential Phytohormones. J Plant Growth Regul. 2018;37:1007-24.

45. Jan S, Alyemeni MN, Wijaya L, Alam P, Siddique KH, Ahmad P. Interactive effect of 24-epibrassinolide and silicon alleviates cadmium stress via the modulation of antioxidant defense and glyoxalase systems and macronutrient content in Pisum Sativum L. seedlings. BMC Plant Biol. 2018;18:146

46. Farooq MA, Gill RA, Islam F, Ali B, Liu H, Xu J, He S, Zhou W. Methyl jasmonate regulates antioxidant defense and suppresses arsenic uptake in Brassica napus L. Front Plant Sci. 2016;7:1-17.
47. Arnao MB, Hernandez-Ruiz J. Assessment of different sample processing procedures applied to the determination of melatonin in plants. Phytochem Anal. 2009a;20:14-8.

48. Korkmaz A, Deger O, Cuci Y. Profiling the melatonin content in organs of the pepper plant during different growth stages. Sci Hortic. 2014;172:242-7.

49. Zhang ZJ, Li HZ, Zhou WJ, Takeuchi Y, Yoneyama K. Effect of 5aminolevulinic acid on development and salt tolerance of potato (Solanum tuberosum L.) microtubers in vitro. Plant Growth Regul. 2006;49:27-34.

50. Yemm EW, Cocking EC. Determination of amino acids with ninhydrin. Analyst. 1955;80:209-13.

51. Bates LS, Waldren RP, Teare ID. Rapid determination of free proline for water stress studies. Plant Soil. 1973;39:205-7.

52. Wang YS, Yang ZM. Nitric oxide reduces aluminum toxicity by preventing oxidative stress in the roots of Cassia tora L. Plant Cell Physiol. 2005;46:1915-23.

53. Zhang WF, Zhang F, Raziuddin R, Gong HJ, Yang ZM, Lu L, Ye QF, Zhou WJ. Effects of 5-aminolevulinic acid on oilseed rape seedling growth under herbicide toxicity stress. J Plant Growth Reg. 2008;27:159-69.

54. Zhou WJ, Leul M. Uniconazole-induced tolerance of rape plants to heat stress in relation to changes in hormonal levels, enzyme activities and lipid peroxidation. Plant Growth Regul. 1999;27:99-104.

55. Aebi H. Catalase in vitro. Methods Enzymol. 1984;105:121-6.

56. Jiang $M$, Zhang J. Water stress-induced abscisic acid accumulation triggers the increased generation of reactive oxygen species and up-regulates the activities of antioxidant enzymes in maize leaves. J Exp Bot. 2002;53:2401-10.

57. Nakano $Y$, Asada K. Hydrogen-peroxide is scavenged by ascorbate-specific peroxidase in spinach-chloroplasts. Plant Cell Physiol. 1981;22:867-80.

58. Kumar A, Singh RP, Singh PK, Awasthi S, Chakrabarty D, Trivedi PK, Tripathi $\mathrm{RD}$. Selenium ameliorates arsenic induced oxidative stress through modulation of antioxidant enzymes and thiols in rice (Oryza sativa L.). Ecotoxicology. 2014;23:1153-63.

59. Duan GL, Hu Y, Liu WJ, Kneer R, Zhao FJ, Zhu YG. Evidence for a role of phytochelatins in regulating arsenic accumulation in rice grain. Environ Exp Bot. 2011;71:416-21.

60. Livak KJ, Schmittgen TD. Analysis of relative gene expression data using real-time quantitative PCR and the $2-\Delta \Delta C T$ method. Methods. 2001;25: 402-8.

61. Tang QY, Zhang CX. Data processing system (DPS) software with experimental design, statistical analysis and data mining developed for use in entomological research. Insect Science. 2013;20:254-60.

62. Ding F, Liu B, Zhang S. Exogenous melatonin ameliorates cold-induced damage in tomato plants. Sci Horti. 2017;219:264-71

63. Ni J, Wang Q, Shah FA, Liu W, Wang D, Huang S, Fu S, Wu L. Exogenous melatonin confers cadmium tolerance by counterbalancing the hydrogen peroxide homeostasis in wheat seedlings. Molecules. 2018;23:1-18.

64. Han QH, Huang B, Ding CB, Zhang ZW, Chen YE, Hu C, Zhou LJ, Huang Y, Liao JQ, Yuan S, Yuan M. Effects of melatonin on anti-oxidative systems and photosystem II in cold-stressed rice seedlings. Front Plant Sci. 2017;8:1-14.

65. Na Z, Bing Z, Hai-Jun Z, Sarah W, Chen Y, Zi-Cai Y, Shuxin R, Yang-Dong G. Melatonin promotes water-stress tolerance, lateral root formation, and seed germination in cucumber (Cucumis sativus L.). J Pineal Res. 2013;54:15-23.

66. Li X, Brestic M, Tan DX, Zivcak M, Zhu X, Liu S, Song F, Reiter RJ, Liu F. Melatonin alleviates low PS I-limited carbon assimilation under elevated $\mathrm{CO}_{2}$ and enhances the cold tolerance of offspring in chlorophyll b-deficient mutant wheat. J Pineal Res. 2018;64:1-49.

67. Zhao D, Wang R, Meng J, Li Z, Wu Y, Tao J. Ameliorative effects of melatonin on dark-induced leaf senescence in gardenia (Gardenia jasminoides Ellis): leaf morphology, anatomy, physiology and transcriptome. Sci Rep. 2017;7:1-19.

68. Yang $X L, X u H$, Li D, Gao X, Li TL, Wang R. Effect of melatonin priming on photosynthetic capacity of tomato leaves under low-temperature stress. Photosynthetica. 2018;56:884-92.

69. Oukarroum A, Bussotti F, Goltsev V, Kalaji HM. Correlation between reactive oxygen species production and photochemistry of photosystems I and II in Lemna gibba L. plants under salt stress. Environ Exp Bot. 2015;109:80-8.

70. Wang P, Sun X, Li C, Wei Z, Liang D, Ma F. Long-term exogenous application of melatonin delays drought-induced leaf senescence in apple. J Pineal Res. 2013;54:292-302.

71. Meng JF, Xu TF, Wang ZZ, Fang YL, Xi ZM, Zhang ZW. The ameliorative effects of exogenous melatonin on grape cuttings under water-deficient stress: antioxidant metabolites, leaf anatomy, and chloroplast morphology. J Pineal Res. 2014;57:200-12. 
72. Turk H, Erdal S, Genisel M, Atici O, Demir Y, Yanmis D. The regulatory effect of melatonin on physiological, biochemical and molecular parameters in cold-stressed wheat seedlings. Plant Growth Reg. 2014;74:139-52.

73. Chen YE, Mao JJ, Sun LQ, Huang B, Ding CB, Gu Y, Liao JQ, Hu C, Zhang $Z W$, Yuan $S$, Yuan M. Exogenous melatonin enhances salt stress tolerance in maize seedlings by improving antioxidant and photosynthetic capacity. Physiol Plant. 2018;164:349-63.

74. Ding F, Wang G, Wang M, Zhang S. Exogenous melatonin improves tolerance to water deficit by promoting cuticle formation in tomato plants. Molecules. 2018;23:1-10.

75. Ashraf M, Foolad MR. Roles of glycine betaine and proline in improving plant abiotic stress resistance. Environ Exp Bot. 2007;59:206-16.

76. Latef A. Arafat a, Tran LSP. Impacts of priming with silicon on the growth and tolerance of maize plants to alkaline stress. Front Plant Sci. 2016;7:1-10.

77. Chang B, Yang L, Cong W, Zu Y, Tang Z. The improved resistance to high salinity induced by trehalose is associated with ionic regulation and osmotic adjustment in Catharanthus roseus. Plant Physiol Biochem. 2014;77:140-8.

78. Van Hoewyk D. A tale of two toxicities: malformed selenoproteins and oxidative stress both contribute to selenium stress in plants. Annals Bot. 2013;112:965-72.

79. Liu Z, Cai JS, Li J, Lu GY, Li CS, Fu GP, Zhang XK, Liu QY, Zou XL, Cheng Y. Exogenous application of a low concentration of melatonin enhances salt tolerance in rapeseed (Brassica napus L) seedlings. J Integr Agr. 2018;17:328-35.

80. Ali B, Gill RA, Yang S, Gill MB, Faroog MA, Liu D, Daud MK, Ali S, Zhou WJ. Regulation of cadmium-induced proteomic and metabolic changes by 5 aminolevulinic acid in leaves of Brassica napus L. PLoS One. 2015;10:1-23.

81. Anjum NA, Hasanuzzaman M, Hossain MA, Thangavel P, Roychoudhury A, Gill SS, Rodrigo MAM, Adam V, Fujita M, Kizek R, Duarte AC. Jacks of metal/metalloid chelation trade in plants-an overview. Front Plant Sci. 2015;6:1-18.

82. Tripathi P, Tripathi RD, Singh RP, Dwivedi S, Goutam D, Shri M, Trivedi PK, Chakrabarty D. Silicon mediates arsenic tolerance in rice (Oryza sativa L.) through lowering of arsenic uptake and improved antioxidant defense system. Ecolog Eng. 2013;52:96-103.

83. Mishra S, Tripathi RD, Srivastava S, Dwivedi S, Trivedi PK, Dhankher OP, Khare A. Thiol metabolism play significant role during cadmium detoxification by ceratophyllum demersum L. Bioresour Technol. 2009;100: 2155-61.

84. Dixit G, Singh AP, Kumar A, Singh PK, Kumar S, Dwivedi S, Trivedi PK, Pandey V, Norton GJ, Dhankher OP, Tripathi RD. Sulfur mediated reduction of arsenic toxicity involves efficient thiol metabolism and the antioxidant defense system in rice. J Hazard Mater. 2015;298:241-51.

\section{Publisher's Note}

Springer Nature remains neutral with regard to jurisdictional claims in published maps and institutional affiliations.

Ready to submit your research? Choose BMC and benefit from:

- fast, convenient online submission

- thorough peer review by experienced researchers in your field

- rapid publication on acceptance

- support for research data, including large and complex data types

- gold Open Access which fosters wider collaboration and increased citations

- maximum visibility for your research: over $100 \mathrm{M}$ website views per year

At $\mathrm{BMC}$, research is always in progress.

Learn more biomedcentral.com/submissions 